BMC

Cancer

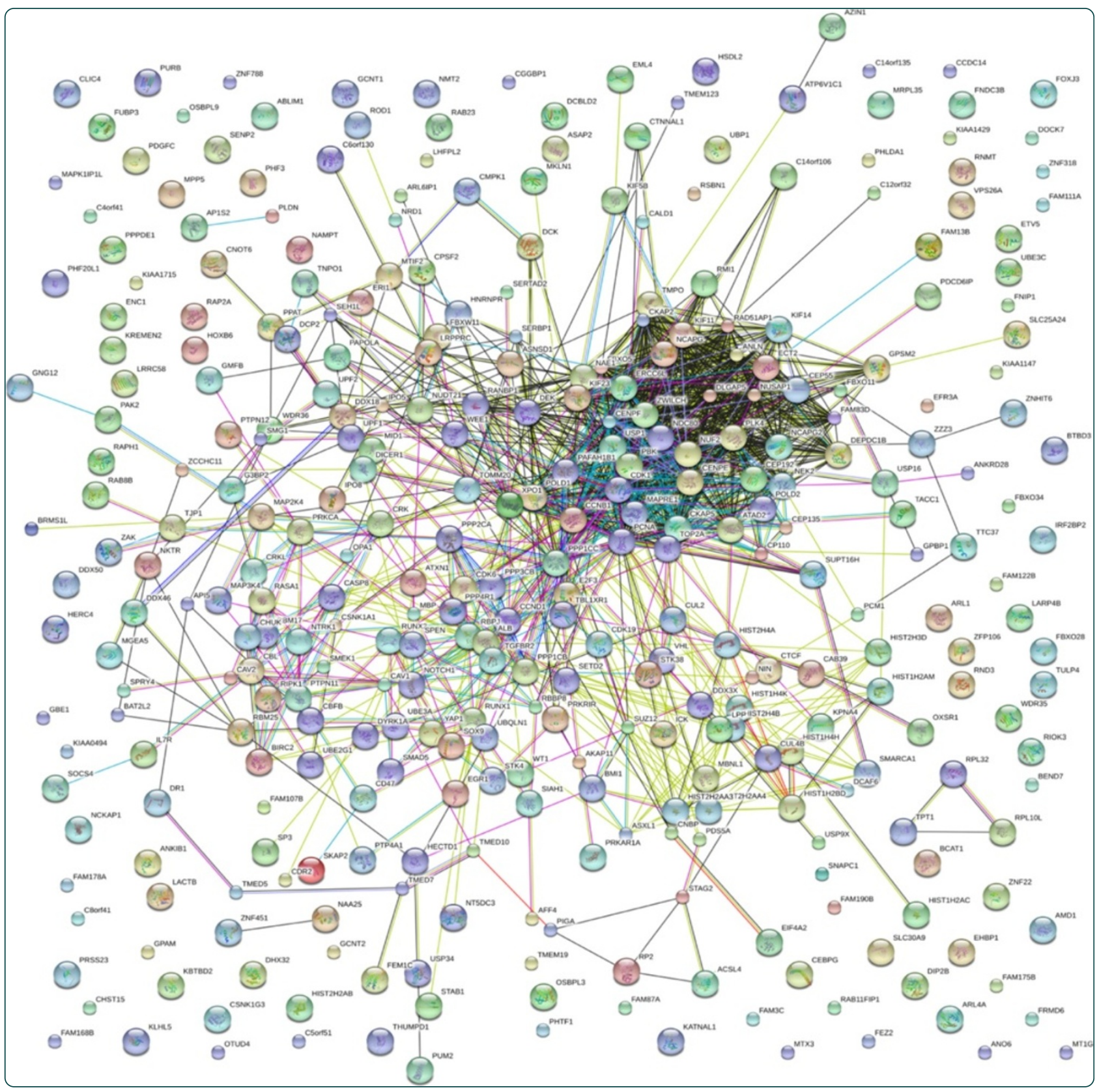

\title{
A genomics approach to identify susceptibilities of breast cancer cells to "fever-range"
} hyperthermia

Amaya et al. 


\title{
A genomics approach to identify susceptibilities of breast cancer cells to "fever-range" hyperthermia
}

\author{
Clarissa Amaya', Vittal Kurisetty ${ }^{1}$, Jessica Stiles ${ }^{1}$, Alice M Nyakeriga' ${ }^{1}$ Arunkumar Arumugam', \\ Rajkumar Lakshmanaswamy ${ }^{1}$, Cristian E Botez ${ }^{2}$, Dianne C Mitchell ${ }^{1}$ and Brad A Bryan ${ }^{1^{*}}$
}

\begin{abstract}
Background: Preclinical and clinical studies have shown for decades that tumor cells demonstrate significantly enhanced sensitivity to "fever range" hyperthermia (increasing the intratumoral temperature to $42-45^{\circ} \mathrm{C}$ ) than normal cells, although it is unknown why cancer cells exhibit this distinctive susceptibility.

Methods: To address this issue, mammary epithelial cells and three malignant breast cancer lines were subjected to hyperthermic shock and microarray, bioinformatics, and network analysis of the global transcription changes was subsequently performed.

Results: Bioinformatics analysis differentiated the gene expression patterns that distinguish the heat shock response of normal cells from malignant breast cancer cells, revealing that the gene expression profiles of mammary epithelial cells are completely distinct from malignant breast cancer lines following this treatment. Using gene network analysis, we identified altered expression of transcripts involved in mitotic regulators, histones, and non-protein coding RNAs as the significant processes that differed between the hyperthermic response of mammary epithelial cells and breast cancer cells. We confirmed our data via qPCR and flow cytometric analysis to demonstrate that hyperthermia specifically disrupts the expression of key mitotic regulators and G2/M phase progression in the breast cancer cells.

Conclusion: These data have identified molecular mechanisms by which breast cancer lines may exhibit enhanced susceptibility to hyperthermic shock.
\end{abstract}

Keywords: Breast cancer, Hyperthermia, Heat shock, Microarray, Genomics, Gene expression

\section{Background}

Although the effectiveness of standard therapies such as surgery, chemotherapy, and irradiation has steadily improved over the years, cancer remains one of the most challenging problems of modern medicine. Among the major issues that complicate cancer treatment is the fact that cancerous cells are very difficult to therapeutically target with any specificity as they are in many respects similar to normal cells and have an astonishing ability of "hiding" their peculiarities. It has been known for over three decades that tumor cells demonstrate significantly

\footnotetext{
* Correspondence: brad.bryan@ttuhsc.edu

'Department of Biomedical Sciences, Paul L. Foster School of Medicine, Texas Tech University Health Sciences Center, 5001 El Paso Drive, MSB1 Room 2111, El Paso, Texas 79905, USA

Full list of author information is available at the end of the article
}

more sensitivity to mild hyperthermia in "fever-range" temperatures $\left(41-45^{\circ} \mathrm{C}\right)$ than normal cells [1,2]. Mild hyperthermia has been shown in a wealth of preclinical oncology studies to act as a dose modifying agent that increases the therapeutic ratio of conventional therapy, thus enhancing the effectiveness of a given dose without additional toxicity [3]. Furthermore, numerous clinical trials have combined hyperthermia with radiation therapy and/ or chemotherapy for many types of carcinomas (including breast cancers) and sarcomas, and most studies have shown a significant reduction in tumor volume when hyperthermia is combined with standard treatments [4-7]. Various hyperthermia techniques have been developed to treat breast cancer, including focused ultrasound [8], focused microwaves $[9,10]$, and radiofrequency electric fields [11]. Despite these techniques, various factors including

\section{Biomed Central}


tumor size and depth greatly affect the homogenous distribution of heat specific to and throughout the entire tumor mass. With the recent and rapid progression of nanobiotechnology applications in medicine, the development of magnetic nanoparticles which can induce tumor hyperthermia through hysteresis loss in an alternating magnetic field has renewed great interest in reexamining this adjuvant therapy in tumor treatments [12]. Further development of this technology may have the potential to overcome the previous limitations associated with older modalities of inducing hyperthermia and lead to reduced morbidity and mortality for patients.

Hyperthermia over a short period (generally 30 minutes to 1 hour) has been shown to induce irreversible cell damage and subsequent death in tumor cells, yet normal cells are remarkably spared [1,2]. These effects are often very rapid, with tumor apoptosis and necrosis occurring within a short time (3-6 hrs) post heating [13]. Several mechanisms have been proposed as to how hyperthermia kills tumor cells including disruption of plasma membrane protein and cytoskeletal distribution, altering mitochondrial membrane potential and cellular redox status, disrupting cell cycle progression, inducing tumor hypoxia, and affecting DNA damage repair mechanisms in the nucleus [14-16], yet despite several decades of research the definitive identification of mechanisms leading to the favorable clinical results of hyperthermia have not been established. It has been further hypothesized that the strong anti-tumor effect of hyperthermia may be due to the low blood flow rate (and thus reduced dispersant cooling following heating) found in the center of tumors due to a disorganized and often dysfunctional vascular system. Additionally, several reports indicate that hyperthermia induces a strong immunological response via activation of immune cells and sensitization of tumor cells to immune effector cells [17-19]. Several studies have elucidated the heat shock induced changes in global gene expression of tumor cell lines such as squamous cell carcinoma, lymphoma, and glioma and have commonly identified gene networks involved in apoptosis, cell cycle, and cell structure/ maintanence [20-22]. However, none of these studies compared the gene expression profiles to that of hyperthermia treated normal cells, thus it remains unknown how the hyperthermic response of cancer cells differs from that of normal cells. Identification of the unique hyperthermiainduced gene expression changes between normal and cancer cells may not only shed light on the selective disadvantage of solid tumors in response to mild increases in temperature, but could also identify signaling targets and biological processes which potentially could be exploited to sensitize tumors to chemotherapy and radiation.

To address this issue, we analyzed the hyperthermiainduced global gene expression profiles of a panel of breast cancer and mammary epithelial cell lines and used bioinformatics analysis to identify the unique gene networks distinct between the normal and cancer lines following this treatment. Furthermore, we confirmed our identified gene expression changes using qPCR and utilized flow cytometry to verify that these transcriptional alterations indeed reflect breast cancer specific responses to hyperthermia.

\section{Methods}

\section{Cell culture and hyperthermia treatment}

MCF10A (ATCC \#CRL10318) mammary epithelial cells and MCF7 luminal breast cancer cells (ATCC \#HTB-22), MDA-MB-231 Basal B breast cancer cells (ATCC \# HTB-26), and MDA-MB-468 Basal A breast cancer cells (ATCC \#HTB-132) were purchased from ATCC and grown in standard culture conditions as previously reported [23-25]. For heat shock, cells were split into two groups: $37^{\circ} \mathrm{C}$ control ( $C$ and $C^{\prime}$ for mammary epithelial and breast cancer cells, respectively) and $45^{\circ} \mathrm{C}$ hyperthermic treatment ( $H$ and $H^{\prime}$ for mammary epithelial and breast cancer cells, respectively). The $37^{\circ} \mathrm{C}$ control was grown under standard culture conditions. For the hyperthermia treatment, $45^{\circ} \mathrm{C}$ prewarmed conditioned media was immediately added to each treatment group and continuously maintained at this temperature for 30 minutes. After this time, the $45^{\circ} \mathrm{C}$ media was completely removed and replaced with $37^{\circ} \mathrm{C}$ conditioned media. The cells were then grown under standard culture conditions and harvested at the time point indicated for each experiment.

\section{Microarray analysis}

Total RNA was collected from each cell line (triplicate biological replicates) 4 hours after completion of the hyperthermia treatment. RNA was amplified and biotinlabeled using Illumina TotalPrep RNA Amplification Kit (Ambion). $750 \mathrm{ng}$ of biotinylated aRNA was then briefly heat-denatured and loaded onto expression arrays to hybridize overnight (triplicate technical replicates). Following hybridization, arrays were labeled with Cy3-streptavidin and imaged on the Illumina ISCAN. Intensity values were transferred to GeneSpring GX microarray analysis software (Agilent) and data was filtered based on quality of each call. Statistical relevance was determined using ANOVA with a Benjamini Hochberg FDR multiple testing correction ( $\mathrm{p}$-value $<0.05$ ). Data were then limited by fold change analysis to statistically relevant data points demonstrating a 2-fold or more change in expression. The microarray data from this experiment is publically available on the Gene Expression Omnibus (GEO Accession \#GSE48398). All heatmaps shown represent the combined average of all biological and technical replicates. 


\section{Bioinformatics analysis of microarray data}

Pathway analysis to identify gene networks and biological processes affected by the gene expression changes was performed using Metacore software (Thomson Reuters). Protein-protein interaction networks were determined using String 9.05 (http://string-db.org).

\section{Quantitative real time PCR analysis}

RNA was isolated from cells 4 hours after the hyperthermia treatment using the Ambion Purelink Minikit according to the manufacturer's directions. The RNA collected was from an independent biological experiment separate from the
RNA collected for the microarray to minimize the discovery of false positives. qRT-PCR was performed on an ABI7900HT RT-PCR system using TaqMan Assays with predesigned primer sets for the genes of interest (Invitrogen). All RT-PCR experiments were performed in at least triplicate.

\section{Flow cytometry}

Cells were harvested 24 hours post treatment via trypsinization and stained with propidium iodide as previous reported [26]. Cell cycle profiles were independently obtained using either a BD LSRII flow cytometer or an Accuri C6

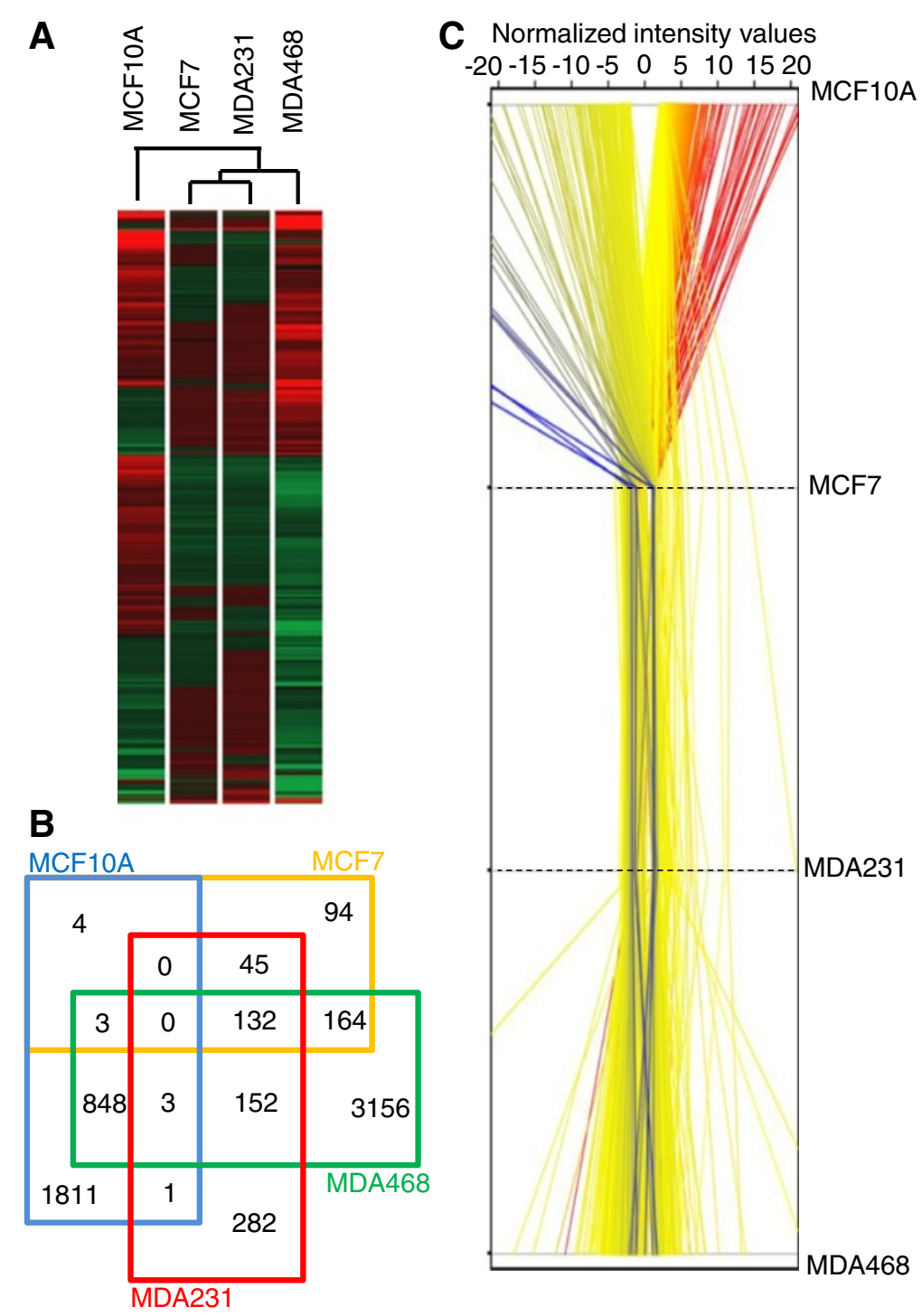

Figure 1 Fever range hyperthermic shock induces large-scale changes in gene expression in breast cancer and mammary epithelial cells. (A) Heatmap depicting the 7252 two-fold or greater changes in gene expression $(p<0.05)$ occurring in the $C$ vs $H$ and $C^{\prime}$ vs $H^{\prime}$ comparisons. Hierarchical clustering based on cell lines shows the degree of similarity with respect to gene expression clustering for each indicated cell line (red $=$ overexpressed, green $=$ underexpressed). (B) Venn diagram illustrating common and unique 2-fold or greater gene expression changes $(p<0.05)$ between each of the cell lines in the $\mathrm{C}$ vs $\mathrm{H}$ and $\mathrm{C}^{\prime}$ vs $\mathrm{H}^{\prime}$ comparison. (C) Profile plot of the normalized intensity values for each two-fold or greater gene expression change $(p<0.05)$ showing relative expression for each cell line in the in the $C$ vs $H$ and $C^{\prime}$ vs $H^{\prime}$ comparison. 
Table 1 List of the top and bottom most regulated genes for each cell line in the $\boldsymbol{C}$ vs $\boldsymbol{H}$ and $\boldsymbol{C}^{\prime}$ vs $\boldsymbol{H}^{\prime}$ comparisons

\begin{tabular}{|c|c|c|c|c|c|c|}
\hline Gene symbol & Gene name & Accession number & MCF-10A & MCF-7 & MDA-231 & MDA-468 \\
\hline \multicolumn{7}{|l|}{ MCF10A } \\
\hline XAGE1A & $\mathrm{X}$ antigen family, member $1 \mathrm{~A}$, TV3 & NM_001097593.1 & 64.0 & 1.2 & 1.0 & 122.0 \\
\hline XAGE1B & $\mathrm{X}$ antigen family, member $1 \mathrm{~B}, \mathrm{TV} 1$ & NM_001097595.1 & 60.3 & 1.2 & 1.1 & 131.6 \\
\hline SRGN & Serglycin, TV1 & NM_002727.2 & 58.1 & 1.1 & -1.5 & 65.8 \\
\hline SRGN & Serglycin, TV1 & NM_002727.2 & 56.5 & 1.2 & -1.5 & 67.7 \\
\hline LOC652683 & $\begin{array}{l}\text { Similar to sperm protein associated with the nucleus, } \\
\quad \text { X chromosome, family member B1 }\end{array}$ & XM_942283.2 & 50.0 & 1.2 & -1.0 & 71.5 \\
\hline SPANXA2 & SPANX family, member A2 & NM_145662.2 & 49.3 & 1.2 & -1.1 & 67.7 \\
\hline SPANXB1 & SPANX family, member B1 & NM_032461.2 & 48.7 & 1.2 & -1.0 & 70.0 \\
\hline TOP2A & Topoisomerase (DNA) II alpha 170 kDa & NM_001067.2 & 39.0 & -2.0 & -3.7 & 1.1 \\
\hline LOC653219 & Similar to $G$ antigen, family $D, 2$ isoform $1 \mathrm{a}$, TV1 & XM_927237.1 & 37.0 & 1.2 & 1.1 & 71.8 \\
\hline LOC100133171 & Hypothetical protein LOC100133171 & XM_001713741.1 & 34.8 & 1.3 & -1.1 & 52.7 \\
\hline RN5S9 & RNA, 5 S ribosomal 9 & NR_023371.1 & -48.2 & 11.5 & 59.7 & 11.5 \\
\hline RN7SK & RNA, 7SK small nuclear & NR_001445.1 & -55.1 & 13.1 & 45.4 & 38.6 \\
\hline SERPINB5 & $\begin{array}{c}\text { Serpin peptidase inhibitor, clade B (ovalbumin), } \\
\text { member } 5\end{array}$ & NM_002639.3 & -65.8 & 1.2 & 7.6 & -3.8 \\
\hline KIAA1666 & KIAA1666 protein & XM_942124.2 & -72.9 & 17.9 & 33.4 & 35.3 \\
\hline AKR1C2 & Aldo-keto reductase family 1 , member $C 2$, TV1 & NM_001354.4 & -82.3 & 1.4 & 24.4 & -9.6 \\
\hline LOC650517 & Hypothetical LOC650517 & XR_019109.1 & -90.0 & 1.2 & 1.7 & -2.0 \\
\hline RN7SK & RNA, 7SK small nuclear & NR_001445.1 & -109.9 & 20.2 & 62.1 & 45.2 \\
\hline KRT17P3 & Predicted misc_RNA KRT17P3 & XR_015626.2 & -133.2 & 1.5 & 2.6 & -4.5 \\
\hline LOC651397 & Predicted misc_RNA LOC651397 & XR_037048.1 & -141.4 & 1.2 & 5.1 & -4.1 \\
\hline KRT6A & Keratin $6 \mathrm{~A}$ & NM_005554.3 & -242.8 & 1.2 & 116.7 & -11.7 \\
\hline \multicolumn{7}{|l|}{ MCF7 } \\
\hline RNY5 & RNA, Ro-associated Y5 & NR_001571.2 & -17.4 & 22.6 & 4.6 & 4.3 \\
\hline RN7SK & RNA, 7SK small nuclear & NR_001445.1 & -109.9 & 20.2 & 62.1 & 45.2 \\
\hline KIAA1666 & KIAA1666 protein & XM_942124.2 & -72.9 & 17.9 & 33.4 & 35.3 \\
\hline MIR1974 & MicroRNA 1974 & NR_031738.1 & -9.4 & 14.2 & 20.8 & 133.3 \\
\hline LOC100008589 & $28 \mathrm{~S}$ ribosomal RNA & NR_003287.1 & -26.8 & 13.8 & 26.4 & 113.8 \\
\hline RN7SK & RNA, 7SK small nuclear & NR_001445.1 & -55.1 & 13.1 & 45.4 & 38.6 \\
\hline LOC100132394 & Hypothetical protein LOC100132394 & XM_001713809.1 & -19.4 & 12.3 & 22.2 & 105.0 \\
\hline RNU4-1 & RNA, U4 small nuclear 1 & NR_003925.1 & -7.7 & 11.5 & 11.4 & 13.2 \\
\hline RN5S9 & RNA, 5 S ribosomal 9 & NR_023371.1 & -48.2 & 11.5 & 59.7 & 11.5 \\
\hline SNORD3C & Small nucleolar RNA, C/D box $3 C$ & NR_006881.1 & -34.9 & 11.1 & 30.5 & 11.8 \\
\hline CCDC117 & Coiled-coil domain containing 117 & NM_173510.1 & 3.2 & -3.3 & -1.7 & -1.8 \\
\hline LOC730432 & Hypothetical protein LOC730432 & XM_001125680.1 & 3.7 & -3.3 & -1.3 & -4.7 \\
\hline LOC644799 & Hypothetical protein LOC644799, TV1 & XM_934554.1 & 2.5 & -3.3 & -2.1 & 1.1 \\
\hline RPS6KB1 & Ribosomal protein S6 kinase, 70 kDa, polypeptide 1 & NM_003161.2 & 2.9 & -3.4 & -1.8 & -3.7 \\
\hline NRIP1 & Nuclear receptor interacting protein 1 & NM_003489.2 & 1.1 & -3.4 & -1.8 & -4.2 \\
\hline AP4E1 & Adaptor-related protein complex 4, epsilon 1 subunit & NM_007347.3 & 2.3 & -3.4 & -2.1 & -2.2 \\
\hline DCP2 & DCP2 decapping enzyme homolog (S. cerevisiae), TV1 & NM_152624.4 & 3.1 & -3.4 & -2.4 & -6.8 \\
\hline TROVE2 & TROVE domain family, member 2, TV1 & NM_001042369.1 & 2.0 & -3.8 & -1.2 & -8.2 \\
\hline PURB & Purine-rich element binding protein $B$ & NM_033224.3 & 3.2 & -3.8 & -2.6 & -7.1 \\
\hline ZNF217 & Zinc finger protein 217 & NM_006526.2 & 3.2 & -3.9 & -1.7 & -2.5 \\
\hline
\end{tabular}




\begin{tabular}{|c|c|c|c|c|c|c|}
\hline \multicolumn{7}{|l|}{ MDA231 } \\
\hline KRT6A & Keratin $6 \mathrm{~A}$ & NM_005554.3 & -242.8 & 1.2 & 116.7 & -11.7 \\
\hline RN7SK & RNA, 7SK small nuclear & NR_001445.1 & -109.9 & 20.2 & 62.1 & 45.2 \\
\hline RN5S9 & RNA, 5 S ribosomal 9 & NR_023371.1 & -48.2 & 11.5 & 59.7 & 11.5 \\
\hline RN7SK & RNA, 7SK small nuclear & NR_001445.1 & -55.1 & 13.1 & 45.4 & 38.6 \\
\hline SNORD3D & Small nucleolar RNA, C/D box 3D & NR_006882.1 & -47.2 & 11.1 & 36.8 & 9.4 \\
\hline SNORD3A & Small nucleolar RNA, C/D box 3A & NR_006880.1 & -46.0 & 11.1 & 36.5 & 9.0 \\
\hline KIAA1666 & KIAA1666 protein & XM_942124.2 & -72.9 & 17.9 & 33.4 & 35.3 \\
\hline SNORD3C & Small nucleolar RNA, C/D box $3 \mathrm{C}$ & NR_006881.1 & -34.9 & 11.1 & 30.5 & 11.8 \\
\hline LOC100008589 & $28 \mathrm{~S}$ ribosomal RNA & NR_003287.1 & -26.8 & 13.8 & 26.4 & 113.8 \\
\hline LOC100132564 & Hypothetical protein LOC100132564 & XM_001713808.1 & -21.6 & 8.4 & 25.3 & 13.3 \\
\hline PAK2 & p21 protein (Cdc42/Rac)-activated kinase 2 & NM_002577.3 & 5.9 & -2.9 & -3.1 & -1.3 \\
\hline CEP55 & Centrosomal protein $55 \mathrm{kDa}$, TV1 & NM_018131.3 & 19.2 & -1.7 & -3.2 & -1.2 \\
\hline RHOBTB3 & Rho-related BTB domain containing 3 & NM_014899.3 & 14.0 & -1.1 & -3.2 & 2.5 \\
\hline ZAK & Sterile alpha motif and leucine zipper containing kinase AZK, V2 & NM_133646.2 & 2.8 & -2.6 & -3.2 & -4.0 \\
\hline KATNAL1 & Katanin p60 subunit A-like 1, TV2 & NM_001014380.1 & 3.6 & -1.4 & -3.2 & -1.3 \\
\hline PBK & PDZ binding kinase & NM_018492.2 & 10.5 & -1.9 & -3.3 & -1.0 \\
\hline PAFAH1B1 & Platelet-activating factor acetylhydrolase, isoform Ib, alpha subunit & NM_000430.2 & 4.5 & -2.6 & -3.5 & 1.2 \\
\hline TOP2A & Topoisomerase (DNA) II alpha 170 kDa & NM_001067.2 & 39.0 & -2.0 & -3.7 & 1.1 \\
\hline FAM83D & Family with sequence similarity 83, member $D$ & NM_030919.2 & 15.4 & -1.8 & -4.0 & -1.7 \\
\hline BCAT1 & Branched chain aminotransferase 1 , cytosolic & NM_005504.4 & 8.9 & 1.1 & -4.9 & 2.9 \\
\hline \multicolumn{7}{|l|}{ MDA468 } \\
\hline MIR1974 & microRNA 1974 & NR_031738.1 & -9.4 & 14.2 & 20.8 & 133.3 \\
\hline XAGE1B & $\mathrm{X}$ antigen family, member 1B, TV1 & NM_001097595.1 & 60.3 & 1.2 & 1.1 & 131.6 \\
\hline XAGE1A & $\mathrm{X}$ antigen family, member $1 \mathrm{~A}$, TV3 & NM_001097593.1 & 64.0 & 1.2 & 1.0 & 122.0 \\
\hline LOC100008589 & $28 \mathrm{~S}$ ribosomal RNA & NR_003287.1 & -26.8 & 13.8 & 26.4 & 113.8 \\
\hline LOC100132394 & Hypothetical protein LOC100132394 & XM_001713809.1 & -19.4 & 12.3 & 22.2 & 105.0 \\
\hline CST3 & Cystatin C & NM_000099.2 & -1.8 & 1.2 & 1.7 & 103.9 \\
\hline ACTG1 & Actin, gamma 1 & NM_001614.2 & 1.1 & 1.5 & 1.5 & 75.2 \\
\hline LOC653219 & Similar to $\mathrm{G}$ antigen, family $\mathrm{D}, 2$ isoform 1a, & XM_927237.1 & 37.0 & 1.2 & 1.1 & 71.8 \\
\hline LOC652683 & $\begin{array}{c}\text { Similar to sperm protein associated with the nucleus, } \\
\quad X \text { chromosome, family member B1 }\end{array}$ & XM_942283.2 & 50.0 & 1.2 & -1.0 & 71.5 \\
\hline SPANXB1 & SPANX family, member B1 & NM_032461.2 & 48.7 & 1.2 & -1.0 & 70.0 \\
\hline CSAG1 & Chondrosarcoma associated gene 1, TVb & NM_153479.1 & 1.7 & 1.2 & -1.0 & -27.4 \\
\hline SERPINA3 & $\begin{array}{c}\text { Serpin peptidase inhibitor, } \\
\text { clade A (alpha-1 antiproteinase, antitrypsin), member } 3\end{array}$ & NM_001085.4 & -8.5 & 1.1 & 2.0 & -30.5 \\
\hline ALDH1A3 & Aldehyde dehydrogenase 1 family, member A3 & NM_000693.1 & -1.5 & -1.0 & 2.0 & -34.0 \\
\hline EPCAM & Epithelial cell adhesion molecule & NM_002354.2 & 1.6 & -1.2 & -1.2 & -36.1 \\
\hline LAD1 & Ladinin 1 & NM_005558.3 & -47.9 & 1.2 & 13.5 & -37.5 \\
\hline OLFML3 & Olfactomedin-like 3 & NM_020190.2 & -1.2 & 1.2 & 1.2 & -39.0 \\
\hline TACSTD1 & Tumor-associated calcium signal transducer 1 & NM_002354.1 & 2.1 & -1.1 & -1.4 & -47.5 \\
\hline RARRES1 & Retinoic acid receptor responder (tazarotene induced) 1, TV1 & NM_206963.1 & -1.3 & 1.3 & -1.1 & -49.9 \\
\hline MGP & Matrix Gla protein & NM_000900.2 & -18.6 & 1.0 & 2.4 & -51.1 \\
\hline KLK5 & Kallikrein-related peptidase 5, TV1 & NM_012427.4 & -1.3 & 1.1 & 1.1 & -56.3 \\
\hline
\end{tabular}




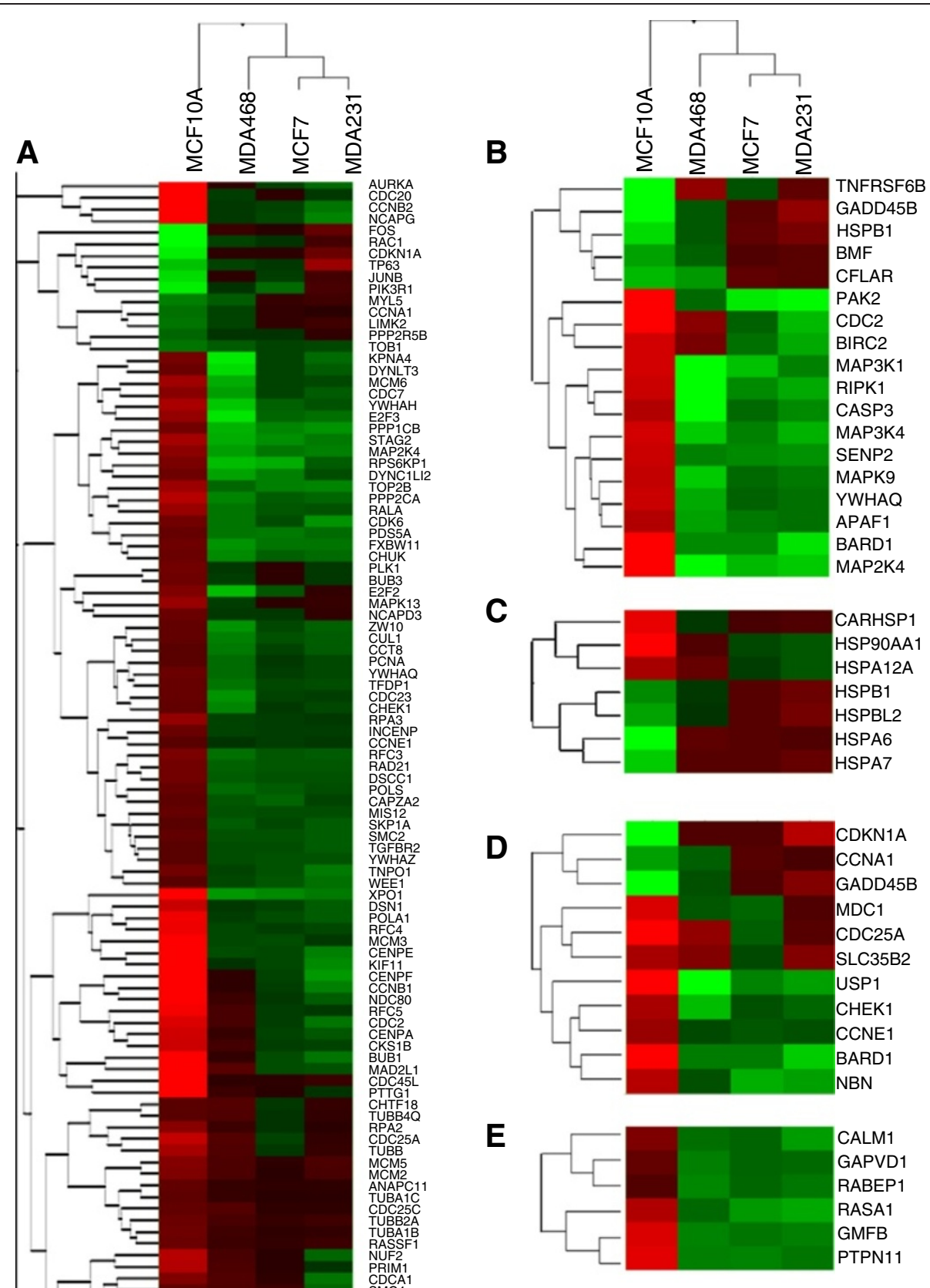

Figure 2 Mammary epithelial cells respond to fever range hyperthermia through transcriptional alterations in gene networks unique from that of breast cancer cells. Hierarchical clustered heatmaps depicting the transcriptional expression changes for genes involved in cell cycle (A), apoptosis (B), heatshock (C), DNA damage (D), and Ran/Rab (E) regulation in the C vs $H$ and $C^{\prime}$ vs $H^{\prime}$ comparison (red =overexpressed, green $=$ underexpressed). 
Table 2 List of genes involved in the gene networks that are differentially regulated between mammary epithelial cells in the ( $C$ vs $H$ and $C^{\prime}$ vs $\left.H^{\prime}\right)$ comparison

\begin{tabular}{|c|c|c|c|c|c|c|}
\hline Gene symbol & Gene name & Accession number & MCF-10A & MCF-7 & MDA-231 & MDA-468 \\
\hline \multicolumn{7}{|l|}{ DNA Damage } \\
\hline USP1 & Ubiquitin specific peptidase 1 , TV3 & NM_001017416.1 & 4.8 & -1.8 & -2.2 & -5.3 \\
\hline CDC25A & Cell division cycle 25A, TV1 & NM_001789.2 & 4.6 & -1.3 & 1.2 & 2.0 \\
\hline BARD1 & BRCA1 associated RING domain 1 & NM_000465.1 & 3.5 & -1.7 & -2.8 & -1.7 \\
\hline MDC1 & Mediator of DNA-damage checkpoint 1 & NM_014641.1 & 3.0 & -1.4 & 1.1 & -1.2 \\
\hline NBN & Nibrin & NM_002485.4 & 2.5 & -2.4 & -2.2 & -1.1 \\
\hline SLC35B2 & Solute carrier family 35 , member B2 & NM_178148.1 & 2.3 & -1.0 & 1.8 & 1.8 \\
\hline CHEK1 & Checkpoint kinase 1, TV3 & NM_001274.3 & 2.3 & -1.1 & -1.4 & -2.6 \\
\hline CCNE1 & Cyclin E1, TV2 & NM_057182.1 & 2.1 & -1.2 & -1.1 & -1.0 \\
\hline CCNA1 & Cyclin A1, TV1 & NM_003914.2 & -2.2 & 1.2 & 1.0 & -1.3 \\
\hline GADD45B & Growth arrest and DNA-damage-inducible, beta & NM_015675.2 & -3.8 & 1.1 & 1.8 & -1.1 \\
\hline CDKN1A & Cyclin-dependent kinase inhibitor 1A (p21, Cip1), TV1 & NM_000389.2 & -4.7 & 1.1 & 2.5 & 1.1 \\
\hline \multicolumn{7}{|l|}{ Cell Cycle } \\
\hline AURKA & Aurora kinase A, TV5 & NM_198436.1 & 22.0 & -1.3 & -2.1 & 1.2 \\
\hline CDC20 & Cell division cycle 20 & NM_001255.2 & 18.0 & 1.1 & -1.1 & -1.2 \\
\hline CCNB2 & Cyclin B2 & NM_004701.2 & 17.5 & -1.3 & -2.3 & -1.1 \\
\hline NCAPG & Non-SMC condensin I complex, subunit G, TV1 & NM_022346.3 & 14.9 & -1.4 & -2.6 & -1.1 \\
\hline BUB1 & Budding uninhibited by benzimidazoles 1 homolog (yeast) & NM_004336.2 & 10.8 & -1.5 & -2.3 & 1.2 \\
\hline MAD2L1 & MAD2 mitotic arrest deficient-like 1 (yeast) & NM_002358.2 & 9.8 & -1.5 & -1.6 & 2.1 \\
\hline CDC45L & Cell division cycle 45, TV2 & NM_003504.3 & 8.0 & 1.1 & 1.4 & 1.1 \\
\hline CENPF & Centromere protein F, 350/400 kDa & NM_016343.3 & 7.8 & -1.3 & -3.0 & 1.1 \\
\hline PTTG1 & Pituitary tumor-transforming 1 & NM_004219.2 & 7.2 & 1.0 & -1.0 & 1.4 \\
\hline MCM3 & Minichromosome maintenance complex component 3, TV1 & NM_002388.3 & 7.2 & -1.5 & -1.1 & -1.4 \\
\hline CCNB1 & Cyclin B1 & NM_031966.2 & 6.9 & -1.2 & -2.5 & 1.1 \\
\hline CENPE & Centromere protein $\mathrm{E}, 312 \mathrm{kDa}$ & NM_001813.2 & 6.6 & -1.4 & -2.5 & -1.5 \\
\hline KIF11 & Kinesin family member 11 & NM_004523.2 & 6.5 & -1.4 & -2.7 & -1.0 \\
\hline NDC80 & NDC80 kinetochore complex component & NM_006101.1 & 6.5 & -1.1 & -1.8 & 1.4 \\
\hline XPO1 & Exportin 1 (CRM1 homolog, yeast) & NM_003400.3 & 6.1 & -2.7 & -2.4 & -3.0 \\
\hline RFC5 & Replication factor C (activator 1) 5, 36.5 kDa, TV1 & NM_007370.3 & 5.8 & -1.2 & -1.1 & 1.7 \\
\hline POLA1 & Polymerase (DNA directed), alpha 1, catalytic subunit & NM_016937.2 & 5.7 & -1.5 & -1.8 & -1.2 \\
\hline RFC4 & Replication factor C (activator 1) 4, $37 \mathrm{kDa}$, TV2 & NM_181573.1 & 5.6 & -1.2 & -1.4 & -1.4 \\
\hline CDC2 & Cyclin-dependent kinase 1, TV1 & NM_001786.2 & 5.2 & -1.2 & -2.3 & 1.7 \\
\hline CENPA & Centromere protein A, TV2 & NM_001042426.1 & 4.9 & -1.3 & -1.7 & 1.3 \\
\hline CKS1B & $\mathrm{CDC} 28$ protein kinase regulatory subunit $1 \mathrm{~B}, \mathrm{TV} 1$ & NM_001826.1 & 4.8 & -1.2 & -1.3 & 1.6 \\
\hline DSN1 & MIND kinetochore complex component, TV3 & NM_024918.2 & 4.7 & -1.3 & -1.8 & -1.1 \\
\hline CDC25A & Cell division cycle 25A, TV1 & NM_001789.2 & 4.6 & -1.3 & 1.2 & 2.0 \\
\hline NUF2 & NDC80 kinetochore complex component, TV2 & NM_031423.3 & 4.3 & 1.0 & -2.0 & 1.7 \\
\hline PPP2CA & Protein phosphatase 2, catalytic subunit, alpha isozyme & NM_002715.2 & 4.3 & -1.8 & -2.0 & -2.6 \\
\hline PRIM1 & Primase, DNA, polypeptide 1 (49 kDa) & NM_000946.2 & 4.2 & 1.0 & -1.0 & 1.8 \\
\hline YWHAH & $\begin{array}{l}\text { Tyrosine 3-monooxygenase/tryptophan 5-monooxygenase } \\
\text { activation protein, eta polypeptide }\end{array}$ & NM_003405.3 & 4.0 & -1.9 & -1.6 & -3.9 \\
\hline TUBB & Tubulin, beta class I & NM_178014.2 & 3.9 & -1.1 & 1.3 & 1.9 \\
\hline STAG2 & Stromal antigen 2, TV2 & NM_001042750.1 & 3.9 & -2.8 & -2.4 & -3.4 \\
\hline CSE1L & CSE1 chromosome segregation 1-like (yeast), TV2 & NM_177436.1 & 3.8 & -1.4 & -1.6 & 1.3 \\
\hline
\end{tabular}


Table 2 List of genes involved in the gene networks that are differentially regulated between mammary epithelial cells in the ( $\mathrm{C}$ vs $\boldsymbol{H}$ and $\mathrm{C}^{\prime}$ vs $\boldsymbol{H}^{\prime}$ ) comparison (Continued)

\begin{tabular}{|c|c|c|c|c|c|c|}
\hline MCM6 & Minichromosome maintenance complex component 6 & NM_005915.4 & 3.8 & -1.3 & -1.4 & -3.4 \\
\hline RPA1 & Replication protein A1, $70 \mathrm{kDa}$ & NM_002945.2 & 3.7 & -1.3 & -1.2 & 1.1 \\
\hline TOP2B & Topoisomerase (DNA) II beta 180 kDa & NM_001068.2 & 3.7 & -2.5 & -2.6 & -2.0 \\
\hline RALA & V-ral simian leukemia viral oncogene homolog A (ras related) & NM_005402.2 & 3.6 & -1.7 & -1.6 & -2.3 \\
\hline SPC25 & SPC25, NDC80 kinetochore complex component & NM_020675.3 & 3.6 & -1.1 & -1.4 & 1.4 \\
\hline MAPK13 & Mitogen-activated protein kinase 13, TV1 & NM_002754.3 & 3.6 & 1.1 & 1.3 & -1.2 \\
\hline RPA3 & Replication protein A3, $14 \mathrm{kDa}$ & NM_002947.3 & 3.5 & -1.2 & -1.1 & -1.3 \\
\hline E2F3 & E2F transcription factor 3, TV1 & NM_001949.2 & 3.5 & -2.0 & -2.2 & -4.5 \\
\hline MCM10 & Minichromosome maintenance complex component 10, TV2 & NM_018518.3 & 3.4 & -1.2 & -1.2 & 2.3 \\
\hline NEK2 & NIMA-related kinase 2, TV1 & NM_002497.2 & 3.4 & -1.1 & -2.1 & 1.1 \\
\hline MAP2K4 & Mitogen-activated protein kinase kinase 4 & NM_003010.2 & 3.3 & -2.3 & -2.5 & -3.1 \\
\hline DYNC1H1 & Dynein, cytoplasmic 1, heavy chain 1 & NM_001376.2 & 3.3 & -2.1 & -1.1 & 1.2 \\
\hline KIF22 & Kinesin family member 22, TV1 & NM_007317.1 & 3.2 & -1.1 & -1.1 & 1.1 \\
\hline RPA2 & Replication protein A2, $32 \mathrm{kDa}$ & NM_002946.3 & 3.2 & -1.0 & 1.0 & 1.4 \\
\hline CDC7 & Cell division cycle 7, TV1 & NM_003503.2 & 3.2 & -1.3 & -1.8 & -3.1 \\
\hline RBL1 & Retinoblastoma-like 1 (p107), TV1 & NM_002895.2 & 3.2 & -1.1 & -2.0 & 1.4 \\
\hline MCM5 & Minichromosome maintenance complex component 5 & NM_006739.3 & 3.1 & 1.1 & 1.8 & 1.8 \\
\hline TGFB2 & Transforming growth factor, beta 2 & NM_003238.1 & 3.0 & 1.2 & -1.4 & 1.7 \\
\hline E2F2 & E2F transcription factor 2 & NM_004091.2 & 3.0 & -1.7 & 1.2 & -3.7 \\
\hline CDCA1 & Cell division cycle associated 1, TV1 & NM_145697.1 & 3.0 & 1.1 & -2.3 & 1.9 \\
\hline ITGB1 & $\begin{array}{c}\text { Integrin, beta } 1 \text { (fibronectin receptor, beta polypeptide, } \\
\text { antigen CD29 includes MDF2, MSK12), TV1 }\end{array}$ & NM_002211.2 & 3.0 & -1.7 & -1.2 & 1.4 \\
\hline MCM2 & Minichromosome maintenance complex component 2, TV1 & NM_004526.2 & 3.0 & 1.0 & 1.7 & 1.8 \\
\hline RFC3 & Replication factor C (activator 1) 3, 38 kDa, TV1 & NM_002915.3 & 2.9 & -1.7 & -1.8 & -2.2 \\
\hline NEDD8 & Neural precursor cell expressed, developmentally down-regulated 8 & NM_006156.2 & 2.9 & -1.1 & -1.0 & 1.4 \\
\hline BIRC5 & Baculoviral IAP repeat containing 5, TV3 & NM_001012271.1 & 2.9 & -1.1 & -1.4 & 1.2 \\
\hline RPS6KB1 & Ribosomal protein S6 kinase, 70 kDa, polypeptide 1, TV1 & NM_003161.2 & 2.9 & -3.4 & -1.8 & -1.2 \\
\hline KPNA4 & Karyopherin alpha 4 (importin alpha 3) & NM_002268.3 & 2.8 & -1.3 & -2.1 & -1.1 \\
\hline PPP1CB & Protein phosphatase 1, catalytic subunit, beta isozyme, TV3 & NM_206876.1 & 2.7 & -2.6 & -2.9 & -1.1 \\
\hline PLK1 & Polo-like kinase 1 & NM_005030.3 & 2.7 & 1.1 & -1.1 & 1.2 \\
\hline CDK6 & Cyclin-dependent kinase 6, TV1 & NM_001259.5 & 2.7 & -1.5 & -2.9 & 2.1 \\
\hline NEK6 & NIMA-related kinase 6, TV2 & NM_014397.3 & 2.7 & 1.1 & -1.2 & 1.1 \\
\hline KPNB1 & Karyopherin (importin) beta 1, TV1 & NM_002265.4 & 2.7 & -1.2 & -1.2 & 1.1 \\
\hline RAD21 & RAD21 homolog (S. pombe) & NM_006265.1 & 2.7 & -1.7 & -1.7 & 1.4 \\
\hline DSCC1 & Defective in sister chromatid cohesion 1 & NM_024094.1 & 2.7 & -1.6 & -1.6 & -1.4 \\
\hline TNPO1 & Transportin 1, TV2 & NM_153188.2 & 2.7 & -1.6 & -2.4 & 1.1 \\
\hline YWHAB & $\begin{array}{c}\text { Tyrosine 3-monooxygenase/tryptophan 5-monooxygenase } \\
\text { activation protein, beta polypeptide, TV1 }\end{array}$ & NM_003404.3 & 2.6 & 1.1 & -1.1 & -1.5 \\
\hline TUBG1 & Tubulin, gamma 1 & NM_001070.3 & 2.6 & 1.0 & -1.0 & -1.0 \\
\hline FBXW11 & F-box and WD repeat domain containing 11, TV1 & NM_033645.2 & 2.6 & -2.3 & -2.3 & 1.4 \\
\hline BUB3 & Budding uninhibited by benzimidazoles 3 homolog (yeast), TV2 & NM_001007793.1 & 2.6 & 1.1 & -1.1 & -3.0 \\
\hline TUBA1B & Tubulin, alpha $1 b$ & NM_006082.2 & 2.6 & 1.1 & 1.2 & 1.7 \\
\hline DYNC1LI2 & Dynein, cytoplasmic 1, light intermediate chain 2 & NM_006141.2 & 2.6 & -2.5 & -1.5 & -1.2 \\
\hline TUBB2A & Tubulin, beta 2A class Ila & NM_001069.2 & 2.5 & 1.3 & 1.5 & -1.4 \\
\hline CHUK & Conserved helix-loop-helix ubiquitous kinase & NM_001278.3 & 2.5 & -1.9 & -2.1 & 1.7 \\
\hline
\end{tabular}


Table 2 List of genes involved in the gene networks that are differentially regulated between mammary epithelial cells in the ( $\mathrm{C}$ vs $\boldsymbol{H}$ and $\mathrm{C}^{\prime}$ vs $\boldsymbol{H}^{\prime}$ ) comparison (Continued)

\begin{tabular}{|c|c|c|c|c|c|c|}
\hline IPO5 & Importin 5 & NM_002271.4 & 2.5 & -1.2 & -2.0 & 1.3 \\
\hline RAN & RAN, member RAS oncogene family & NM_006325.2 & 2.5 & -1.4 & -1.5 & 1.6 \\
\hline RASSF1 & Ras association (RalGDS/AF-6) domain family member 1, TVA & NM_007182.4 & 2.5 & 1.2 & 1.4 & -1.1 \\
\hline INCENP & Inner centromere protein antigens 135/155 kDa, TV1 & NM_001040694.1 & 2.5 & -1.2 & -1.2 & 2.0 \\
\hline DYNLT3 & Dynein, light chain, Tctex-type 3 & NM_006520.1 & 2.5 & -1.3 & -1.8 & 1.7 \\
\hline NCAPD3 & Non-SMC condensin II complex, subunit D3 & NM_015261.2 & 2.5 & -1.1 & 1.2 & -2.6 \\
\hline YWHAQ & $\begin{array}{c}\text { Tyrosine 3-monooxygenase/tryptophan 5-monooxygenase } \\
\text { activation protein, theta polypeptide }\end{array}$ & NM_006826.2 & 2.5 & -1.2 & -1.4 & 1.8 \\
\hline TFDP1 & Transcription factor Dp-1, TV1 & NM_007111.3 & 2.4 & -1.4 & -1.5 & -3.9 \\
\hline PDS5A & PDS5, regulator of cohesion maintenance, TV2 & NM_015200.1 & 2.4 & -2.4 & -2.1 & 1.9 \\
\hline MIS12 & MIS12, MIND kinetochore complex component, TV2 & NM_024039.1 & 2.4 & -1.5 & -1.5 & -3.4 \\
\hline CDC23 & Cell division cycle 23 & NM_004661.3 & 2.4 & -1.3 & -1.2 & 1.3 \\
\hline POLS & PAP associated domain containing 7, TV1 & NM_006999.3 & 2.4 & -1.8 & -1.5 & -3.4 \\
\hline CDC25C & Cell division cycle 25C, TV1 & NM_001790.3 & 2.3 & 1.1 & 1.1 & 1.1 \\
\hline BUB1B & BUB1 mitotic checkpoint serine/threonine kinase $B$ & NM_001211.4 & 2.3 & -1.1 & -1.4 & -2.0 \\
\hline ANAPC11 & Anaphase promoting complex subunit 11, TV4 & NM_001002246.1 & 2.3 & 1.1 & 1.1 & -2.3 \\
\hline CHEK1 & Checkpoint kinase 1, TV3 & NM_001274.3 & 2.3 & -1.1 & -1.4 & 1.4 \\
\hline ZW10 & Zw10 kinetochore protein & NM_004724.2 & 2.3 & -1.4 & -1.9 & -1.2 \\
\hline SMC2 & Structural maintenance of chromosomes 2, TV1 & NM_001042550.1 & 2.3 & -1.6 & -1.8 & -1.3 \\
\hline CUL1 & Cullin 1 & NM_003592.2 & 2.3 & -1.6 & -1.8 & -4.5 \\
\hline TUBA1C & Tubulin, alpha 1c & NM_032704.3 & 2.2 & 1.0 & 1.0 & 2.3 \\
\hline SMC4 & Structural maintenance of chromosomes 4, TV2 & NM_001002800.1 & 2.2 & 1.4 & -2.0 & 1.1 \\
\hline CAPZA2 & Capping protein (actin filament) muscle Z-line, alpha 2 & NM_006136.2 & 2.2 & -2.0 & -1.3 & -3.1 \\
\hline PCNA & Proliferating cell nuclear antigen & NM_182649.1 & 2.1 & -1.1 & -1.4 & 1.2 \\
\hline PPP2R5C & $\begin{array}{c}\text { Protein phosphatase } 2 \text {, regulatory subunit B', } \\
\text { gamma isoform , TV4 }\end{array}$ & NM_178588.1 & 2.1 & -1.0 & -1.2 & 1.1 \\
\hline SKP1A & S-phase kinase-associated protein 1, TV1 & NM_006930.2 & 2.1 & -1.4 & -1.8 & 1.4 \\
\hline TGFBR2 & Transforming growth factor, beta receptor II (70/80 kDa), TV1 & NM_001024847.1 & 2.1 & -1.5 & -1.8 & -3.1 \\
\hline CHTF18 & CTF18, chromosome transmission fidelity factor 18 & NM_022092.1 & 2.1 & -1.1 & 1.3 & 1.4 \\
\hline CCNE1 & Cyclin E1, TV2 & NM_057182.1 & 2.1 & -1.2 & -1.1 & 1.8 \\
\hline YWHAZ & $\begin{array}{l}\text { Tyrosine 3-monooxygenase/tryptophan 5-monooxygenase } \\
\text { activation protein, zeta polypeptide }\end{array}$ & NM_003406.2 & 2.1 & -1.6 & -1.6 & 1.7 \\
\hline ССТ8 & Chaperonin containing TCP1, subunit 8 (theta) & NM_006585.2 & 2.1 & -1.3 & -1.8 & -3.7 \\
\hline TUBB4Q & Tubulin, beta polypeptide 4, member Q, pseudogene & NM_020040.3 & 2.1 & -1.0 & 1.2 & 1.9 \\
\hline WEE1 & WEE1 homolog (S. pombe), TV1 & NM_003390.2 & 2.1 & -1.7 & -2.2 & 1.4 \\
\hline RB1 & Retinoblastoma 1 & NM_000321.2 & 2.0 & -1.4 & -1.7 & 1.8 \\
\hline PPP2R5B & Protein phosphatase 2 , regulatory subunit B', beta & NM_006244.2 & -2.0 & -1.0 & 1.2 & -2.2 \\
\hline CCNA1 & Cyclin A1, TV1 & NM_003914.2 & -2.2 & 1.2 & 1.0 & 1.4 \\
\hline TOB1 & Transducer of ERBB2, 1, TV1 & NM_005749.2 & -2.3 & -1.3 & -1.4 & 1.2 \\
\hline LIMK2 & LIM domain kinase 2, TV1 & NM_001031801.1 & -2.3 & 1.2 & 1.5 & -1.2 \\
\hline MYL5 & Myosin, light chain 5 , regulatory & NM_002477.1 & -2.5 & 1.3 & 1.5 & -1.1 \\
\hline TP63 & Tumor protein p63, TV5 & NM_001114981.1 & -3.8 & -1.1 & 3.7 & -1.1 \\
\hline JUNB & Jun B proto-oncogene & NM_002229.2 & -4.3 & -1.2 & 1.6 & 1.2 \\
\hline PIK3R1 & Phosphoinositide-3-kinase, regulatory subunit 1 (alpha), TV1 & NM_181523.1 & -4.7 & -2.1 & 1.7 & 2.1 \\
\hline CDKN1A & Cyclin-dependent kinase inhibitor 1A (p21, Cip1) & NM_000389.2 & -4.7 & 1.1 & 2.5 & 1.1 \\
\hline
\end{tabular}


Table 2 List of genes involved in the gene networks that are differentially regulated between mammary epithelial cells in the ( $C$ vs $H$ and $C^{\prime}$ vs $H^{\prime}$ ) comparison (Continued)

\begin{tabular}{|c|c|c|c|c|c|c|}
\hline RAC1 & $\begin{array}{l}\text { Ras-related C3 botulinum toxin substrate } 1 \text { (rho family, } \\
\text { small GTP binding protein Rac1), Rac1b }\end{array}$ & NM_018890.2 & -7.6 & -1.0 & 1.6 & 1.1 \\
\hline FOS & FBJ murine osteosarcoma viral oncogene homolog & NM_005252.2 & -14.9 & 1.0 & 2.4 & 1.4 \\
\hline \multicolumn{7}{|l|}{ Apoptosis } \\
\hline PAK2 & p21 protein (Cdc42/Rac)-activated kinase 2 & NM_002577.3 & 6.0 & -2.9 & -3.1 & -1.3 \\
\hline CDC2 & Cyclin-dependent kinase 1, TV1 & NM_001786.2 & 5.2 & -1.2 & -2.3 & 1.7 \\
\hline BARD1 & BRCA1 associated RING domain 1 & NM_000465.1 & 3.5 & -1.7 & -2.8 & -1.7 \\
\hline MAP2K4 & Mitogen-activated protein kinase kinase 4 & NM_003010.2 & 3.3 & -2.3 & -2.5 & -3.1 \\
\hline MAP3K4 & Mitogen-activated protein kinase kinase kinase 4, TV1 & NM_005922.2 & 2.6 & -1.6 & -2.2 & -2.5 \\
\hline MAP3K1 & $\begin{array}{l}\text { Mitogen-activated protein kinase kinase kinase 1, } \\
\text { E3 ubiquitin protein ligase }\end{array}$ & NM_005921.1 & 2.6 & -2.4 & -1.6 & -3.8 \\
\hline $\mathrm{BIRC2}$ & Baculoviral IAP repeat containing 2, TV1 & NM_001166.3 & 2.6 & -1.4 & -2.1 & 1.5 \\
\hline SENP2 & SUMO1/sentrin/SMT3 specific peptidase 2 & NM_021627.2 & 2.5 & -1.7 & -1.8 & -1.6 \\
\hline RIPK1 & Receptor (TNFRSF)-interacting serine-threonine kinase 1 & NM_003804.3 & 2.5 & -1.7 & -2.1 & -4.5 \\
\hline YWHAQ & $\begin{array}{l}\text { Tyrosine 3-monooxygenase/tryptophan 5-monooxygenase } \\
\text { activation protein, theta polypeptide }\end{array}$ & NM_006826.2 & 2.5 & -1.2 & -1.4 & -2.1 \\
\hline MAPK9 & Mitogen-activated protein kinase 9, TV JNK2-a2 & NM_002752.3 & 2.4 & -1.3 & -1.5 & -2.5 \\
\hline CASP3 & Caspase 3, apoptosis-related cysteine peptidase, TV beta & NM_032991.2 & 2.2 & -1.3 & -1.7 & -4.0 \\
\hline APAF1 & Apoptotic peptidase activating factor 1, TV1 & NM_013229.2 & 2.2 & -1.5 & -1.4 & -2.0 \\
\hline BMF & Bcl2 modifying factor, TV2 & NM_033503.3 & -2.0 & 1.0 & 1.1 & -1.2 \\
\hline CFLAR & CASP8 and FADD-like apoptosis regulator & NM_003879.3 & -2.3 & 1.2 & 1.1 & -1.9 \\
\hline HSPB1 & Heat shock 27 kDa protein 1 & NM_001540.2 & -2.7 & 1.2 & 1.5 & -1.1 \\
\hline GADD45B & Growth arrest and DNA-damage-inducible, beta & NM_015675.2 & -3.8 & 1.1 & 1.8 & -1.1 \\
\hline TNFRSF6B & $\begin{array}{l}\text { Tumor necrosis factor receptor superfamily, member 6b, } \\
\text { decoy, transcript variant M68C }\end{array}$ & NM_032945.2 & -4.3 & -1.0 & 1.2 & 1.8 \\
\hline \multicolumn{7}{|l|}{ Heat Shock } \\
\hline HSP90AA1 & Heat shock protein 90 kDa, class A member 1 & NM_001017963.2 & 4.0 & -1.4 & -1.7 & 1.1 \\
\hline CARHSP1 & Calcium regulated heat stable protein 1, $24 \mathrm{kDa}$ & NM_001042476.1 & 3.2 & 1.0 & 1.1 & -1.1 \\
\hline HSPA12A & Heat shock protein $70 \mathrm{kDa} 12 \mathrm{~A}$ & NM_025015.2 & 2.3 & -1.2 & -1.7 & 1.4 \\
\hline HSPB1 & Heat shock protein 27 kDa protein 1 & NM_001540.2 & -2.7 & 1.2 & 1.5 & -1.1 \\
\hline HSPBL2 & Heat shock 27 kDa protein 1 pseudogene 1 & NR_024392.1 & -3.2 & 1.2 & 1.6 & -1.0 \\
\hline HSPA6 & Heat shock 70 kDa protein 6 & NM_002155.3 & -5.3 & 1.2 & 1.1 & 1.3 \\
\hline HSPA7 & Heat shock 70 kDa protein 7 & NR_024151.1 & -4.0 & 1.2 & 1.4 & 1.2 \\
\hline
\end{tabular}

flow cytometer. Flow cytometry data was analyzed using Flowjo software (Tree Star) or CFlow Plus software (Accuri).

\section{Results}

Determination of the global transcriptional response of mammary epithelial and breast cancer cells to fever range hyperthermia

It remains to be determined how mild hyperthermia preferentially selects against breast cancer cells, yet largely spares normal tissue from collateral damage. To address this question, we first sought to elucidate how hyperthermia induces alterations in gene expression patterns in mammary epithelial and breast cancer cells. Mammary epithelial cells (MCF10A) and three malignant breast cancer lines from each of the known subtypes (MCF7 [luminal], MDA231 [Basal B], and MDA468 [Basal A]) were subjected to 30 minutes of fever range hyperthermic shock (or maintained at $37^{\circ} \mathrm{C}$ as a control) as described in the Materials and Methods section. To streamline identification of these treatment groups, cells grown at $37^{\circ} \mathrm{C}$ will be referred to as $C$ and $C^{\prime}$ (for mammary epithelial and breast cancer cells, respectively), while cells grown at $45^{\circ} \mathrm{C}$ will be referred to as $H$ and $H^{\prime}$ (for mammary epithelial and breast cancer cells, respectively). Total RNA was isolated 4 hours following hyperthermic treatment. We then performed microarray analysis of the global transcription changes using Illumina high density BeadArrays which 
measure the expression levels of more than 47,000 transcripts and known splice variants across the human transcriptome. Data was filtered based on quality of each call and statistical relevance was determined using ANOVA with a Benjamini Hochberg FDR multiple testing correction ( $\mathrm{p}$-value $<0.05$ ). Data were then limited by fold change analysis to statistically relevant data points demonstrating a 2 -fold or more change in expression. When comparing the expression changes based on the $C$ vs $H$ and $C^{\prime}$ vs $H^{\prime}$ analysis, we discovered that hyperthermia induced very dramatic changes in gene expression in all cell lines tested as reflected by 7252 two-fold or greater statistically significant gene expression changes $(\mathrm{p}<0.05)$ occurring in at least one of the four cell lines (Figure 1A). Specifically, hyperthermia significantly altered the expression of 2670 genes in the MCF10A line (1810 genes upregulated and 860 genes downregulated), 442 genes in MCF7 (72 genes upregulated and 370 genes downregulated), 615 genes in MDA231 (244 genes upregulated and 371 downregulated), and 4458 genes in MDA468 (1744 genes upregulated and 2714 genes downregulated). A list of the top and bottom most regulated genes for each cell line can be found in Table 1. The complete gene expression dataset has been freely and publically deposited in Gene Expression Omnibus for ease of access and meta-analysis (GEO Accession \#48398). These data suggest that mild hyperthermia induces large-scale alterations in gene expression profiles across normal and breast cancer cell lines.

Hierarchical clustering of the gene expression changes based on each cell line indicates that the breast cancer lines responded to hyperthermia more similarly to each other than to the mammary epithelial line (Figure 1A). Using a Venn diagram that strictly eliminated any genes with less than a 2 -fold expression change $(\mathrm{p}<0.05)$, we compared the gene expression profiles that were shared and unique between each cell line in response to

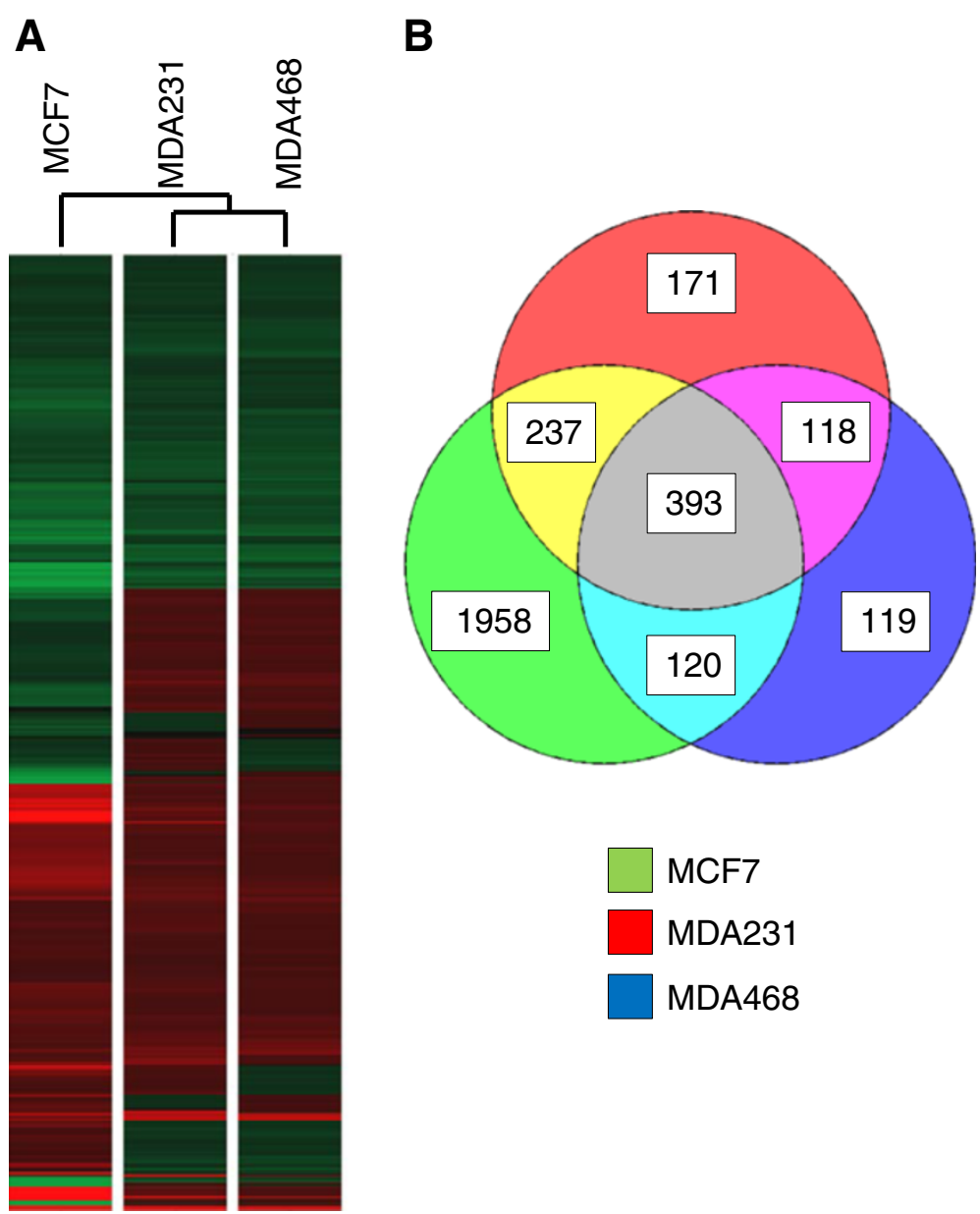

Figure 3 Identification of genes that differentiate the transcriptional response of breast cancer cells following fever range hyperthermia. (A) Heatmap depicting the two-fold or greater changes in gene expression $(p<0.05)$ occurring in at least one of the three breast cancer cell lines (MCF7, MDA231, MDA468) relative to the mammary epithelial cells in the $H^{\prime}$ vs $H$ comparison (red=overexpressed, green = underexpressed). (B) Venn diagram illustrating common and unique 2 -fold or greater gene expression changes $(p<0.05)$ between each of the breast cancer cell lines relative to the mammary epithelial cells in the $H^{\prime}$ vs $H$ comparison. 
Table 3 List of genes that statistically distinguish the hyperthermic response of three breast cancer lines from the mammary epithelial cells in the $H^{\prime}$ vs $H$ analysis

\begin{tabular}{|c|c|c|c|c|c|}
\hline Gene Symbol & Gene Name & Accession Number & MCF-7 & MDA-231 & MDA-468 \\
\hline RN7SK & RNA, 7SK small nuclear & NR_001445.1 & 68.5 & 64.5 & 73.5 \\
\hline RN5S9 & RNA, $5 S$ ribosomal 9 & NR_023371.1 & 54.5 & 64.7 & 64.9 \\
\hline RNU1-3 & RNA, U1 small nuclear 3 & NR_004408.1 & 44.2 & 27.9 & 30.3 \\
\hline RNU1G2 & RNA, U1 small nuclear 4 & NR_004426.1 & 42.5 & 26.4 & 28.5 \\
\hline KIAA1666 & RIMS binding protein 3 & XM_942124.2 & 38.5 & 36.1 & 41.6 \\
\hline RNU1-5 & RNA, U1 small nuclear 5 & NR_004400.1 & 36.5 & 25.1 & 28.1 \\
\hline SNORD3D & Small nucleolar RNA, C/D box 3D & NR_006882.1 & 34.8 & 43.3 & 47.2 \\
\hline RNU1A3 & RNA, U1 small nuclear 1 & NR_004430.1 & 30.2 & 19.9 & 20.3 \\
\hline SNORD3A & Small nucleolar RNA, C/D box 3A & NR_006880.1 & 30.1 & 42.6 & 43.8 \\
\hline SNORD3C & Small nucleolar RNA, C/D box $3 \mathrm{C}$ & NR_006881.1 & 28.4 & 30.9 & 34.7 \\
\hline RNY5 & RNA, Ro-associated Y5 & NR_001571.2 & 27.8 & 4.6 & 4.3 \\
\hline LOC100008589 & RNA28S5 RNA, 285 ribosomal 5 & NR_003287.1 & 27.2 & 28.9 & 30.9 \\
\hline LOC100132564 & Hypothetical Protein LOC100132564 & XM_001713808.1 & 26.7 & 26.5 & 27.3 \\
\hline LOC100132394 & Hypothetical Protein & XP_001713861.1 & 23.8 & 23.1 & 22.9 \\
\hline RNU4-1 & RNA, U4 small nuclear 1 & NR_003925.1 & 18.5 & 11.6 & 13.1 \\
\hline RNU6ATAC & RNA, U6atac small nuclear (U12-dependent splicing) & NR_023344.1 & 16.3 & 11.8 & 12.4 \\
\hline LOC100134364 & Hypothetical Protein LOC100134364 & XM_001713810.1 & 15.9 & 15.5 & 17.2 \\
\hline HIST2H2AA3 & Histone cluster 2, H2aa3 & NM_003516.2 & 15.3 & 3.2 & 3.1 \\
\hline HIST2H2AA4 & Histone cluster 2, H2aa4 & NM_001040874.1 & 13.4 & 3.1 & 2.8 \\
\hline MIR1974 & MicroRNA 1974 & NR_031738.1 & 12.8 & 24.1 & 24.5 \\
\hline RMRP & $\begin{array}{c}\text { RNA component of mitochondrial RNA processing } \\
\text { endoribonuclease }\end{array}$ & NR_003051.2 & 12.1 & 14.1 & 15.6 \\
\hline RNA18S5 & RNA18S5 RNA, 18S ribosomal 5 & NR_003286.1 & 11.4 & 11.9 & 12.6 \\
\hline RNU4-2 & RNA, U4 small nuclear 2 & NR_003137.2 & 10.7 & 5.7 & 6.3 \\
\hline SCARNA20 & Small Cajal body-specific RNA 20 & NR_002999.2 & 7.7 & 3.2 & 3.1 \\
\hline LOC441763 & Hypothetical Protein LOC441763 & XM_930284.1 & 7.4 & 5.9 & 7.2 \\
\hline LOC728688 & Ubiquitin-like, containing PHD and RING finger domains & XM_001724542.1 & 6.6 & 6.1 & 7.3 \\
\hline VTRNA1-1 & Vault RNA 1-1 & NR_026703.1 & 6.5 & 4.4 & 4.1 \\
\hline RNU6-1 & RNA, U6 small nuclear 1 & NR_004394.1 & 6.3 & 6.9 & 7.3 \\
\hline RNU6-15 & RNA, U6 small nuclear 15 & NR_028372.1 & 6.3 & 6.2 & 7.1 \\
\hline ALB & Albumin & NM_000477.3 & 4.9 & 5.3 & 5.5 \\
\hline $\mathrm{HIST} 1 \mathrm{H} 4 \mathrm{H}$ & Histone cluster $1, \mathrm{H} 4 \mathrm{~h}$ & NM_003543.3 & 4.9 & 2.9 & 2.9 \\
\hline $\mathrm{HIST} 2 \mathrm{H} 4 \mathrm{~A}$ & Histone cluster 2, $\mathrm{H} 4 \mathrm{a}$ & NM_003548.2 & 4.6 & 5.1 & 4.7 \\
\hline TRK1 & Transfer RNA lysine 1 (anticodon UUU) & NR_001449.1 & 4.6 & 3.5 & 3.8 \\
\hline SNORD46 & Small nucleolar RNA, C/D box 46 & NR_000024.2 & 4.2 & 3.9 & 3.8 \\
\hline RNU4ATAC & RNA, U4atac small nuclear (U12-dependent splicing) & NR_023343.1 & 4.2 & 3.7 & 3.9 \\
\hline KREMEN2 & Kringle containing transmembrane protein 2 & NM_145348.1 & 4.1 & 2.9 & 2.8 \\
\hline RNU11 & RNA, U11 small nuclear & NR_004407.1 & 3.8 & 2.8 & 2.9 \\
\hline SNORA57 & Small nucleolar RNA, H/ACA box 57 & NR_004390.1 & 3.8 & 4.9 & 5.2 \\
\hline RPPH1 & Ribonuclease P RNA component $\mathrm{H} 1$ & NR_002312.1 & 3.7 & 2.7 & 3.1 \\
\hline SCARNA13 & Small Cajal body-specific RNA 13 & NR_003002.1 & 3.7 & 4.3 & 4.9 \\
\hline RPL12P6 & Ribosomal protein L12 pseudogene 6 & XR_016704.2 & 3.5 & 2.4 & 4.1 \\
\hline LOC389787 & Tumor protein, translationally-controlled 1 pseudogene & XM_497072.2 & 3.4 & 3.1 & 2.1 \\
\hline RPL10L & Ribosomal protein L10-like & NM_080746.2 & 3.3 & 3.6 & 3.7 \\
\hline
\end{tabular}


Table 3 List of genes that statistically distinguish the hyperthermic response of three breast cancer lines from the mammary epithelial cells in the $\boldsymbol{H}^{\prime}$ vs $\boldsymbol{H}$ analysis (Continued)

\begin{tabular}{|c|c|c|c|c|c|}
\hline SNORA7B & Small nucleolar RNA, H/ACA box 7B & NR_002992.2 & 3.2 & 4.8 & 5.1 \\
\hline LOC100132673 & Ribosomal protein S2 pseudogene 28 & XR_039018.1 & 3.1 & 2.3 & 2.6 \\
\hline RNY4 & RNA, Ro-associated Y4 & NR_004393.1 & 3.1 & 5.5 & 4.7 \\
\hline HOXB6 & Homeobox B6 & NM_018952.4 & 2.9 & 4.2 & 4.1 \\
\hline HIST1H4K & Histone cluster 1, H4k & NM_003541.2 & 2.9 & 3.2 & 3.3 \\
\hline SNORA12 & Small nucleolar RNA, H/ACA box 12 & NR_002954.1 & 2.9 & 2.4 & 2.3 \\
\hline LOC643031 & MT-ND5 pseudogene 10 & XM_926402.1 & 2.8 & 2.9 & 3.8 \\
\hline $\mathrm{HIST} 2 \mathrm{H} 4 \mathrm{~B}$ & Histone cluster $2, \mathrm{H} 4 \mathrm{~b}$ & NM_001034077.4 & 2.7 & 2.8 & 2.9 \\
\hline $\mathrm{HIST} 2 \mathrm{H} 3 \mathrm{D}$ & Histone cluster 2, H3d & NM_001123375.1 & 2.3 & 3.7 & 3.9 \\
\hline HIST1H2AC & Histone cluster 1, H2ac & NM_003512.3 & 2.3 & 2.9 & 2.7 \\
\hline EGR1 & Early growth response 1 & NM_001964.2 & 2.3 & 2.8 & 2.4 \\
\hline SNORA63 & Small nucleolar RNA, H/ACA box 63 & NR_002586.1 & 2.3 & 7.8 & 7.3 \\
\hline SNORD13 & Small nucleolar RNA, C/D box 13 & NR_003041.1 & 2.3 & 5.6 & 5.7 \\
\hline RNY1 & RNA, Ro-associated Y1 & NR_004391.1 & 2.1 & 4.4 & 4.1 \\
\hline HIST1H2AM & Histone cluster 1, H2am & NM_003514.2 & 2.1 & 3.1 & 3.5 \\
\hline MARCH7 & $\begin{array}{c}\text { Membrane-associated ring finger 7, } \\
\text { E3 ubiquitin protein ligase }\end{array}$ & NM_022826.2 & -2.0 & -2.3 & -2.3 \\
\hline GPBP1 & GC-rich promoter binding protein 1 & NM_022913.1 & -2.0 & -3.4 & -2.9 \\
\hline RAB11FIP1 & RAB11 family interacting protein 1 (class I) & NM_001002814.1 & -2.0 & -2.0 & -2.8 \\
\hline CEBPG & CCAAT/enhancer binding protein (C/EBP), gamma & NM_001806.2 & -2.0 & -2.0 & -2.5 \\
\hline ZWILCH & Zwilch kinetochore protein & NR_003105.1 & -2.0 & -2.7 & -2.6 \\
\hline DDX18 & DEAD (Asp-Glu-Ala-Asp) box polypeptide 18 & NM_006773.3 & -2.0 & -2.6 & -2.7 \\
\hline PTP4A1 & Protein tyrosine phosphatase type IVA, member 1 & NM_003463.3 & -2.0 & -2.9 & -2.4 \\
\hline DDX3X & DEAD (Asp-Glu-Ala-Asp) box polypeptide 3, X-linked & NM_001356.3 & -2.0 & -2.6 & -2.3 \\
\hline CTCF & CCCTC-binding factor (zinc finger protein) & NM_006565.2 & -2.0 & -2.6 & -2.3 \\
\hline SKAP2 & src kinase associated phosphoprotein 2 & NM_003930.3 & -2.0 & -2.3 & -2.2 \\
\hline ANO6 & Anoctamin 6 & NM_001025356.1 & -2.0 & -2.3 & -2.3 \\
\hline PPAT & Phosphoribosyl pyrophosphate amidotransferase & NM_002703.3 & -2.0 & -2.1 & -2.3 \\
\hline USP34 & Ubiquitin specific peptidase 34 & NM_014709.3 & -2.0 & -2.1 & -2.0 \\
\hline LHFPL2 & Lipoma HMGIC fusion partner-like 2 & NM_005779.1 & -2.1 & -2.1 & -2.1 \\
\hline KIAA1147 & KIAA1147 & NM_001080392.1 & -2.1 & -2.1 & -2.3 \\
\hline KIAA2010 & SMEK homolog 1, suppressor of mek1 (Dictyostelium) & NM_032560.3 & -2.1 & -3.6 & -3.0 \\
\hline DYRK1A & Dual-specificity tyrosine-(Y)-phosphorylation regulated kinase $1 \mathrm{~A}$ & NM_130438.1 & -2.1 & -2.5 & -2.3 \\
\hline RBBP8 & Retinoblastoma binding protein 8 & NM_203291.1 & -2.1 & -2.6 & -2.4 \\
\hline ANKIB1 & Ankyrin repeat and IBR domain containing 1 & NM_019004.1 & -2.1 & -2.5 & -2.5 \\
\hline C12orf32 & RAD9-HUS1-RAD1 interacting nuclear orphan 1 & NM_031465.2 & -2.1 & -2.1 & -2.1 \\
\hline FNIP1 & Folliculin interacting protein 1 & NM_001008738.2 & -2.1 & -2.0 & -2.1 \\
\hline NAE1 & NEDD8 activating enzyme E1 subunit 1 & NM_001018160.1 & -2.2 & -2.0 & -2.3 \\
\hline RSBN1 & Round spermatid basic protein 1 & NM_018364.3 & -2.2 & -2.0 & -2.3 \\
\hline SUPT16H & Suppressor of Ty 16 homolog (S. cerevisiae) & NM_007192.2 & -2.2 & -2.1 & -2.2 \\
\hline TMED10 & Transmembrane emp24-like trafficking protein 10 (yeast) & NM_006827.5 & -2.2 & -3.6 & -2.9 \\
\hline PPP1CB & Protein phosphatase 1, catalytic subunit, beta isozyme & NM_206876.1 & -2.2 & -2.4 & -2.7 \\
\hline ARL6IP1 & ADP-ribosylation factor-like 6 interacting protein 1 & NM_015161.1 & -2.2 & -2.8 & -2.7 \\
\hline ASNSD1 & Asparagine synthetase domain containing 1 & NM_019048.1 & -2.2 & -2.9 & -2.5 \\
\hline
\end{tabular}


Table 3 List of genes that statistically distinguish the hyperthermic response of three breast cancer lines from the mammary epithelial cells in the $\boldsymbol{H}^{\prime}$ vs $\boldsymbol{H}$ analysis (Continued)

\begin{tabular}{|c|c|c|c|c|c|}
\hline NRBF2P4 & Nuclear receptor binding factor 2 pseudogene 4 & XM_001127763.1 & -2.2 & -2.6 & -2.4 \\
\hline ТTC37 & Tetratricopeptide repeat domain 37 & NM_014639.2 & -2.2 & -2.6 & -2.2 \\
\hline DICER1 & Dicer 1 , ribonuclease type III & NM_030621.2 & -2.2 & -2.6 & -2.3 \\
\hline UBE2G1 & Ubiquitin-conjugating enzyme E2G 1 & NM_003342.4 & -2.2 & -2.5 & -2.4 \\
\hline LRPPRC & Leucine-rich pentatricopeptide repeat containing & NM_133259.2 & -2.2 & -2.4 & -2.2 \\
\hline OTUD4 & OTU domain containing 4 & NM_199324.1 & -2.2 & -2.3 & -2.2 \\
\hline FUBP3 & Far upstream element (FUSE) binding protein 3 & NM_003934.1 & -2.2 & -2.3 & -2.2 \\
\hline FAM175B & Family with sequence similarity 175 , member $B$ & NM_032182.3 & -2.2 & -2.1 & -2.1 \\
\hline DDX50 & DEAD (Asp-Glu-Ala-Asp) box polypeptide 50 & NM_024045.1 & -2.2 & -2.0 & -2.1 \\
\hline PIGA & Phosphatidylinositol glycan anchor biosynthesis, class A & NM_020473.2 & -2.2 & -2.0 & -2.2 \\
\hline FAM168B & Family with sequence similarity 168 , member $B$ & NM_001009993.2 & -2.3 & -2.0 & -2.0 \\
\hline FBXO11 & F-box protein 11 & NM_025133.3 & -2.3 & -2.1 & -2.5 \\
\hline SLC25A24 & Solute carrier family 25 (mitochondrial carrier; phosphate carrier), member 24 & NM_013386.3 & -2.3 & -3.4 & -2.5 \\
\hline NCKAP1 & NCK-associated protein 1 & NM_013436.3 & -2.3 & -3.3 & -2.7 \\
\hline FBXW11 & F-box and WD repeat domain containing 11 & NM_033645.2 & -2.3 & -2.5 & -2.7 \\
\hline SLC30A9 & Solute carrier family 30 (zinc transporter), member 9 & NM_006345.3 & -2.3 & -2.0 & -2.7 \\
\hline ATAD2 & ATPase family, AAA domain containing 2 & NM_014109.2 & -2.3 & -2.8 & -2.0 \\
\hline CSNK1A1 & Casein kinase 1, alpha 1 & NM_001025105.1 & -2.3 & -2.5 & -2.2 \\
\hline CHUK & Conserved helix-loop-helix ubiquitous kinase & NM_001278.3 & -2.3 & -2.2 & -2.3 \\
\hline ATP6V1C1 & ATPase, $\mathrm{H}+$ transporting, lysosomal $42 \mathrm{kDa}, \mathrm{V} 1$ subunit C1 & NM_001695.4 & -2.3 & -2.1 & -2.4 \\
\hline CUL2 & Cullin 2 & NM_003591.2 & -2.3 & -2.2 & -2.1 \\
\hline BRMS1L & Breast cancer metastasis-suppressor 1-like & NM_032352.3 & -2.3 & -2.1 & -2.0 \\
\hline UBQLN1 & Ubiquilin 1 & NM_013438.3 & -2.3 & -2.1 & -2.1 \\
\hline OPA1 & Optic atrophy 1 (autosomal dominant) & NM_015560.1 & -2.4 & -2.7 & -2.6 \\
\hline EFR3A & EFR3 homolog A (S. cerevisiae) & NM_015137.3 & -2.4 & -2.3 & -3.2 \\
\hline BAT2D1 & Proline-rich coiled-coil $2 \mathrm{C}$ & NM_015172.3 & -2.4 & -2.5 & -2.1 \\
\hline OSBPL9 & Oxysterol binding protein-like 9 & NM_148906.1 & -2.4 & -2.6 & -2.5 \\
\hline CDR2 & Cerebellar degeneration-related protein 2,62 kDa & NM_001802.1 & -2.4 & -2.3 & -2.2 \\
\hline KPNA4 & Karyopherin alpha 4 (importin alpha 3) & NM_002268.3 & -2.4 & -2.2 & -2.4 \\
\hline ARL1 & ADP-ribosylation factor-like 1 & NM_001177.3 & -2.4 & -2.2 & -2.3 \\
\hline DHX32 & DEAH (Asp-Glu-Ala-His) box polypeptide 32 & NM_018180.2 & -2.4 & -2.1 & -2.3 \\
\hline $\mathrm{RIOK} 3$ & RIO kinase 3 & NM_003831.3 & -2.4 & -2.0 & -2.1 \\
\hline C5orf51 & Chromosome 5 open reading frame 51 & NM_175921.4 & -2.5 & -2.8 & -2.6 \\
\hline TJP1 & Tight junction protein 1 & NM_003257.3 & -2.5 & -2.4 & -2.2 \\
\hline CSNK1G3 & Casein kinase 1, gamma 3 & NM_001031812.2 & -2.5 & -2.4 & -2.3 \\
\hline PREI3 & MOB family member 4 , phocein & NM_199482.1 & -2.5 & -2.4 & -2.4 \\
\hline KIAA0494 & EF-hand calcium binding domain 14 & NM_014774.1 & -2.5 & -2.3 & -2.4 \\
\hline PRKRIR & $\begin{array}{l}\text { Protein-kinase, interferon-inducible double stranded } \\
\text { RNA dependent inhibitor, repressor of (P58 repressor) }\end{array}$ & NM_004705.2 & -2.5 & -2.7 & -3.0 \\
\hline LOC644363 & LOC644363 & XR_016912.2 & -2.5 & -2.6 & -2.9 \\
\hline DCP2 & DCP2 decapping enzyme homolog (S. cerevisiae) & NM_152624.4 & -2.5 & -2.5 & -3.0 \\
\hline ROD1 & Polypyrimidine tract binding protein 3 & NM_005156.4 & -2.5 & -2.9 & -3.2 \\
\hline CRK & v-crk sarcoma virus CT10 oncogene homolog (avian) & NM_016823.2 & -2.5 & -3.3 & -2.8 \\
\hline PRKAR1A & Protein kinase, cAMP-dependent, regulatory, type I, alpha & NM_002734.3 & -2.5 & -2.6 & -2.4 \\
\hline
\end{tabular}


Table 3 List of genes that statistically distinguish the hyperthermic response of three breast cancer lines from the mammary epithelial cells in the $\boldsymbol{H}^{\prime}$ vs $\boldsymbol{H}$ analysis (Continued)

\begin{tabular}{|c|c|c|c|c|c|}
\hline GPSM2 & G-protein signaling modulator 2 & NM_013296.3 & -2.5 & -2.2 & -2.3 \\
\hline API5 & Apoptosis inhibitor 5 & NM_006595.2 & -2.5 & -2.1 & -2.5 \\
\hline CRKL & v-crk sarcoma virus CT10 oncogene homolog (avian)-like & NM_005207.2 & -2.5 & -2.0 & -2.6 \\
\hline CBL & Cbl proto-oncogene, E3 ubiquitin protein ligase & NM_005188.2 & -2.5 & -2.0 & -2.2 \\
\hline SMG1 & smg-1 homolog, phosphatidylinositol 3-kinase-related kinase interferon & NM_015092.3 & -2.6 & -2.9 & -2.6 \\
\hline IRF2BP2 & Regulatory factor 2 binding protein 2 & NM_182972.2 & -2.6 & -2.7 & -2.7 \\
\hline CNOT6 & CCR4-NOT transcription complex, subunit 6 & NM_015455.3 & -2.6 & -2.7 & -2.6 \\
\hline THUMPD1 & THUMP domain containing 1 & NM_017736.3 & -2.6 & -2.6 & -2.5 \\
\hline BMl1 & BMI1 polycomb ring finger oncogene & NM_005180.5 & -2.6 & -2.4 & -2.7 \\
\hline CDC2L6 & Cyclin-dependent kinase 19 & NM_015076.3 & -2.6 & -2.4 & -2.8 \\
\hline TULP4 & Tubby like protein 4 & NM_001007466.1 & -2.6 & -2.3 & -2.6 \\
\hline LARP4B & La ribonucleoprotein domain family, member $4 B$ & NM_015155.1 & -2.6 & -2.3 & -2.3 \\
\hline HECTD1 & HECT domain containing E3 ubiquitin protein ligase 1 & NM_015382.1 & -2.6 & -2.6 & -2.4 \\
\hline CPSF2 & Cleavage and polyadenylation specific factor 2, $100 \mathrm{kDa}$ & NM_017437.1 & -2.6 & -2.8 & -2.6 \\
\hline PDS5A & PDS5, regulator of cohesion maintenance, homolog A (S. cerevisiae) & NM_015200.1 & -2.6 & -2.6 & -2.9 \\
\hline RIPK1 & Receptor (TNFRSF)-interacting serine-threonine kinase 1 & NM_003804.3 & -2.6 & -2.1 & -2.4 \\
\hline DCAF6 & DDB1 and CUL4 associated factor 6 & NM_001017977.1 & -2.6 & -2.1 & -2.4 \\
\hline KIAA1429 & KIAA1429 & NM_015496.3 & -2.6 & -2.0 & -2.3 \\
\hline RUNX1 & Runt-related transcription factor 1 & NM_001754.3 & -2.6 & -2.1 & -2.2 \\
\hline CEP135 & Centrosomal protein $135 \mathrm{kDa}$ & NM_025009.3 & -2.6 & -2.0 & -2.2 \\
\hline MBNL1 & Muscleblind-like splicing regulator 1 & NM_207296.1 & -2.6 & -2.5 & -2.2 \\
\hline RBPJ & Recombination signal binding protein for immunoglobulin kappa J region & NM_203284.1 & -2.6 & -2.4 & -2.0 \\
\hline USP16 & Ubiquitin specific peptidase 16 & NM_006447.2 & -2.6 & -2.2 & -2.1 \\
\hline TOMM20 & Translocase of outer mitochondrial membrane 20 homolog (yeast) & NM_014765.1 & -2.7 & -2.3 & -2.5 \\
\hline MTX3 & Metaxin 3 & NM_001010891.3 & -2.7 & -2.7 & -2.6 \\
\hline RAPH1 & Ras association (RalGDS/AF-6) and pleckstrin homology domains 1 & NM_213589.1 & -2.7 & -2.6 & -2.5 \\
\hline PHF20L1 & PHD finger protein 20-like 1 & NM_016018.4 & -2.7 & -2.6 & -2.7 \\
\hline UBP1 & Upstream binding protein 1 (LBP-1a) & NM_014517.3 & -2.7 & -2.5 & -2.6 \\
\hline GBE1 & Glucan (1,4-alpha-), branching enzyme 1 & NM_000158.2 & -2.7 & -2.4 & -2.3 \\
\hline CUL4B & Cullin 4B & NM_001079872.1 & -2.7 & -2.4 & -2.4 \\
\hline PAPOLA & Poly(A) polymerase alpha & NM_001037281.1 & -2.7 & -2.4 & -2.9 \\
\hline RNMT & RNA (guanine-7-) methyltransferase & NM_003799.1 & -2.7 & -2.1 & -2.4 \\
\hline FBXO34 & F-box protein 34 & NM_017943.2 & -2.7 & -2.3 & -2.1 \\
\hline DOCK7 & Dedicator of cytokinesis 7 & NM_033407.2 & -2.7 & -2.3 & -2.1 \\
\hline BTBD3 & BTB (POZ) domain containing 3 & NM_014962.2 & -2.7 & -2.2 & -2.1 \\
\hline C6orf130 & O-acyl-ADP-ribose deacylase 1 & NM_145063.2 & -2.8 & -2.3 & -2.1 \\
\hline MRPL35 & Mitochondrial ribosomal protein L35 & NM_016622.2 & -2.8 & -2.2 & -2.2 \\
\hline PUM2 & Pumilio homolog 2 (Drosophila) & NM_015317.1 & -2.8 & -2.8 & -2.8 \\
\hline NUDT21 & Nudix (nucleoside diphosphate linked moiety X)-type motif 21 & NM_007006.2 & -2.8 & -2.7 & -2.3 \\
\hline ICK & Intestinal cell (MAK-like) kinase & NM_016513.3 & -2.8 & -2.7 & -2.5 \\
\hline RBM17 & RNA binding motif protein 17 & NM_032905.3 & -2.8 & -2.4 & -2.1 \\
\hline RMl1 & RMI1, RecQ mediated genome instability 1, homolog (S. cerevisiae) & NM_024945.2 & -2.9 & -2.4 & -2.1 \\
\hline MAP2K4 & Mitogen-activated protein kinase kinase 4 & NM_003010.2 & -2.9 & -2.8 & -2.8 \\
\hline G3BP2 & GTPase activating protein (SH3 domain) binding protein 2 & NM_203504.1 & -2.9 & -2.5 & -2.5 \\
\hline
\end{tabular}


Table 3 List of genes that statistically distinguish the hyperthermic response of three breast cancer lines from the mammary epithelial cells in the $\boldsymbol{H}^{\prime}$ vs $\boldsymbol{H}$ analysis (Continued)

\begin{tabular}{|c|c|c|c|c|c|}
\hline NAMPT & Nicotinamide phosphoribosyltransferase & NM_005746.2 & -2.9 & -2.7 & -2.1 \\
\hline BEND7 & BEN domain containing 7 & NM_001100912.1 & -2.9 & -2.2 & -2.1 \\
\hline FEZ2 & Fasciculation and elongation protein zeta 2 (zygin II) & NM_005102.2 & -3.0 & -2.2 & -2.2 \\
\hline ARL4A & ADP-ribosylation factor-like $4 \mathrm{~A}$ & NM_001037164.1 & -3.0 & -2.4 & -2.2 \\
\hline SOCS4 & Suppressor of cytokine signaling 4 & NM_080867.2 & -3.0 & -3.0 & -2.6 \\
\hline STAG2 & Stromal antigen 2 & NM_001042750.1 & -3.0 & -2.9 & -2.5 \\
\hline C14orf32 & Mitogen-activated protein kinase 1 interacting protein 1 -like & NM_144578.2 & -3.0 & -2.9 & -2.9 \\
\hline РPР3СВ & Protein phosphatase 3 , catalytic subunit, beta isozyme & NM_021132.1 & -3.0 & -2.4 & -2.6 \\
\hline RBM25 & RNA binding motif protein 25 & NM_021239.1 & -3.0 & -2.4 & -2.5 \\
\hline ERI1 & Exoribonuclease 1 & NM_153332.3 & -3.0 & -2.0 & -2.3 \\
\hline NRD1 & Nardilysin (N-arginine dibasic convertase) & NM_002525.1 & -3.0 & -2.4 & -2.1 \\
\hline E2F3 & E2F transcription factor 3 & NM_001949.2 & -3.0 & -2.0 & -2.0 \\
\hline ANKRD28 & Ankyrin repeat domain 28 & NM_015199.2 & -3.1 & -2.3 & -2.2 \\
\hline ZAK & Sterile alpha motif and leucine zipper containing kinase AZK & NM_133646.2 & -3.1 & -3.1 & -3.4 \\
\hline HNRPR & Heterogeneous nuclear ribonucleoprotein $\mathrm{R}$ & NM_005826.2 & -3.1 & -2.9 & -2.1 \\
\hline TMEM123 & Transmembrane protein 123 & NM_052932.2 & -3.1 & -2.8 & -2.3 \\
\hline FAM178A & Family with sequence similarity 178 , member $\mathrm{A}$ & NM_018121.3 & -3.1 & -2.7 & -2.6 \\
\hline EML4 & Echinoderm microtubule associated protein like 4 & NM_019063.2 & -3.1 & -2.6 & -2.6 \\
\hline FOXJ3 & Forkhead box J3 & NM_014947.3 & -3.1 & -2.5 & -2.5 \\
\hline NT5DC3 & 5'-nucleotidase domain containing 3 & NM_016575.1 & -3.1 & -2.3 & -2.6 \\
\hline LPP & LIM domain containing preferred translocation partner in lipoma & NM_005578.2 & -3.1 & -2.2 & -3.5 \\
\hline RND3 & Rho family GTPase 3 & NM_005168.3 & -3.1 & -2.0 & -2.2 \\
\hline WDR36 & WD repeat domain 36 & NM_139281.2 & -3.1 & -2.0 & -2.2 \\
\hline CDCA1 & NUF2, NDC80 kinetochore complex component & NM_145697.1 & -3.1 & -2.5 & -2.0 \\
\hline PRSS23 & Protease, serine, 23 & NM_007173.4 & -3.2 & -2.3 & -2.0 \\
\hline ERCC6L & $\begin{array}{l}\text { Excision repair cross-complementing rodent repair deficiency, } \\
\text { complementation group 6-like }\end{array}$ & NM_017669.2 & -3.2 & -2.3 & -2.0 \\
\hline FAM122B & Family with sequence similarity $122 \mathrm{~B}$ & NM_032448.1 & -3.3 & -2.5 & -2.0 \\
\hline CKAP5 & Cytoskeleton associated protein 5 & NM_001008938.1 & -3.3 & -2.2 & -2.1 \\
\hline CGGBP1 & CGG triplet repeat binding protein 1 & NM_001008390.1 & -3.3 & -2.8 & -3.5 \\
\hline TBL1XR1 & Transducin (beta)-like 1 X-linked receptor 1 & NM_024665.3 & -3.3 & -3.1 & -2.7 \\
\hline LOC644799 & LOC644799 & XM_934554.1 & -3.3 & -3.0 & -2.5 \\
\hline DCK & Deoxycytidine kinase & NM_000788.1 & -3.3 & -2.8 & -2.2 \\
\hline SERBP1 & SERPINE1 mRNA binding protein 1 & NM_030666.2 & -3.3 & -2.1 & -3.3 \\
\hline PPP1CC & Protein phosphatase 1, catalytic subunit, gamma isozyme & NM_002710.1 & -3.3 & -2.2 & -2.1 \\
\hline KIF5B & Kinesin family member $5 B$ & NM_004521.1 & -3.4 & -4.1 & -3.3 \\
\hline AFF4 & AF4/FMR2 family, member 4 & NM_014423.3 & -3.4 & -3.6 & -3.5 \\
\hline MPP5 & Membrane protein, palmitoylated 5 (MAGUK p55 subfamily member 5) & NM_022474.2 & -3.4 & -3.1 & -2.7 \\
\hline IPO5 & Importin 5 & NM_002271.4 & -3.4 & -2.6 & -2.2 \\
\hline HNRNPR & Heterogeneous nuclear ribonucleoprotein $\mathrm{R}$ & NM_005826.3 & -3.4 & -2.6 & -2.3 \\
\hline CP110 & Centriolar coiled coil protein $110 \mathrm{kDa}$ & NM_014711.3 & -3.4 & -2.5 & -2.5 \\
\hline FEM1C & fem-1 homolog c (C. elegans) & NM_020177.2 & -3.4 & -2.4 & -2.5 \\
\hline PHTF1 & Putative homeodomain transcription factor 1 & NM_006608.1 & -3.4 & -2.3 & -2.1 \\
\hline RAD51AP1 & RAD51 associated protein 1 & NM_006479.3 & -3.4 & -2.2 & -2.0 \\
\hline
\end{tabular}


Table 3 List of genes that statistically distinguish the hyperthermic response of three breast cancer lines from the mammary epithelial cells in the $\boldsymbol{H}^{\prime}$ vs $\boldsymbol{H}$ analysis (Continued)

\begin{tabular}{|c|c|c|c|c|c|}
\hline MAPRE1 & Microtubule-associated protein, RP/EB family, member 1 & NM_012325.1 & -3.4 & -2.1 & -2.1 \\
\hline TMPO & Thymopoietin & NM_003276.1 & -3.5 & -3.1 & -2.3 \\
\hline LACTB & Lactamase, beta & NM_032857.2 & -3.5 & -2.3 & -2.3 \\
\hline DDX46 & DEAD (Asp-Glu-Ala-Asp) box polypeptide 46 & NM_014829.2 & -3.5 & -2.3 & -2.4 \\
\hline SPEN & Spen homolog, transcriptional regulator (Drosophila) & NM_015001.2 & -3.5 & -2.0 & -2.7 \\
\hline TMEM19 & Transmembrane protein 19 & NM_018279.3 & -3.5 & -2.1 & -2.0 \\
\hline CBFB & Core-binding factor, beta subunit & NM_001755.2 & -3.5 & -2.2 & -2.2 \\
\hline IPO8 & Importin 8 & NM_006390.2 & -3.5 & -2.2 & -2.1 \\
\hline WT1 & Wilms tumor 1 & NM_024426.3 & -3.5 & -2.4 & -2.1 \\
\hline CKAP2 & Cytoskeleton associated protein 2 & NM_001098525.1 & -3.6 & -3.0 & -2.4 \\
\hline WEE1 & WEE1 homolog (S. pombe) & NM_003390.2 & -3.6 & -2.8 & -2.7 \\
\hline PDCD6IP & Programmed cell death 6 interacting protein & NM_013374.3 & -3.6 & -2.7 & -2.3 \\
\hline ZNF788 & Zinc finger family member 788 & XR_041527.1 & -3.6 & -2.6 & -2.3 \\
\hline RAP2A & RAP2A, member of RAS oncogene family & NM_021033.5 & -3.6 & -2.3 & -2.7 \\
\hline MGEA5 & Meningioma expressed antigen 5 (hyaluronidase) & NM_012215.2 & -3.6 & -2.1 & -2.7 \\
\hline UBE3A & Ubiquitin protein ligase E3A & NM_000462.2 & -3.6 & -2.0 & -2.8 \\
\hline PLK4 & Polo-like kinase 4 & NM_014264.3 & -3.7 & -3.8 & -3.2 \\
\hline RP2 & Retinitis pigmentosa 2 (X-linked recessive) & NM_006915.1 & -3.7 & -2.9 & -2.5 \\
\hline SETD2 & SET domain containing 2 & NM_014159.4 & -3.7 & -2.7 & -2.8 \\
\hline KLHL5 & Kelch-like family member 5 & NM_001007075.1 & -3.7 & -2.4 & -2.6 \\
\hline KBTBD2 & Kelch repeat and BTB (POZ) domain containing 2 & NM_015483.1 & -3.7 & -3.7 & -3.1 \\
\hline USP9X & Ubiquitin specific peptidase 9, X-linked & NM_001039591.2 & -3.8 & -2.8 & -2.4 \\
\hline RAB23 & RAB23, member RAS oncogene family & NM_016277.3 & -3.8 & -2.6 & -2.5 \\
\hline DR1 & Down-regulator of transcription 1, TBP-binding (negative cofactor 2) & NM_001938.2 & -3.8 & -2.3 & -2.2 \\
\hline RAB8B & RAB8B, member RAS oncogene family & NM_016530.2 & -3.8 & -2.3 & -2.5 \\
\hline ZNF451 & Zinc finger protein 451 & NM_001031623.2 & -3.8 & -2.2 & -2.4 \\
\hline ZZZ3 & Zinc finger, ZZ-type containing 3 & NM_015534.4 & -3.9 & -3.1 & -3.3 \\
\hline CDC2 & Cyclin-dependent kinase 1 & NM_001786.2 & -4.0 & -2.9 & -2.3 \\
\hline ZFP106 & Zinc finger protein 106 & NM_022473.1 & -4.0 & -3.0 & -2.5 \\
\hline CAB39 & Calcium binding protein 39 & NM_016289.2 & -4.0 & -2.0 & -3.1 \\
\hline TNPO1 & Transportin 1 & NM_153188.2 & -4.0 & -2.9 & -2.5 \\
\hline MAP3K4 & Mitogen-activated protein kinase kinase kinase 4 & NM_005922.2 & -4.1 & -2.3 & -2.7 \\
\hline ECT2 & Epithelial cell transforming sequence 2 oncogene & NM_018098.4 & -4.1 & -2.3 & -2.0 \\
\hline TMED5 & Transmembrane emp24 protein transport domain containing 5 & NM_016040.3 & -4.1 & -2.3 & -2.1 \\
\hline SEH1L & SEH1-like (S. cerevisiae) & NM_001013437.1 & -4.1 & -2.7 & -2.5 \\
\hline NCAPG2 & Non-SMC condensin II complex, subunit G2 & NM_017760.5 & -4.2 & -2.7 & -2.2 \\
\hline USP1 & Ubiquitin specific peptidase 1 & NM_001017416.1 & -4.2 & -2.3 & -2.4 \\
\hline OXSR1 & Oxidative-stress responsive 1 & NM_005109.2 & -4.2 & -2.3 & -2.4 \\
\hline PTPN12 & Protein tyrosine phosphatase, non-receptor type 12 & NM_002835.2 & -4.2 & -2.8 & -2.8 \\
\hline CMPK1 & Cytidine monophosphate (UMP-CMP) kinase 1, cytosolic & NM_016308.1 & -4.2 & -2.5 & -2.4 \\
\hline PAFAH1B1 & Platelet-activating factor acetylhydrolase $1 \mathrm{~b}$, regulatory subunit 1 (45 kDa) & NM_000430.2 & -4.3 & -3.8 & -3.1 \\
\hline PURB & Purine-rich element binding protein B & NM_033224.3 & -4.3 & -2.5 & -3.5 \\
\hline STK4 & Serine/threonine kinase 4 & NM_006282.2 & -4.3 & -2.3 & -3.3 \\
\hline KATNAL1 & Katanin p60 subunit A-like 1 & NM_001014380.1 & -4.3 & -3.1 & -2.9 \\
\hline
\end{tabular}


Table 3 List of genes that statistically distinguish the hyperthermic response of three breast cancer lines from the mammary epithelial cells in the $\boldsymbol{H}^{\prime}$ vs $\boldsymbol{H}$ analysis (Continued)

\begin{tabular}{|c|c|c|c|c|c|}
\hline NIN & Ninein (GSK3B interacting protein) & NM_020921.3 & -4.3 & -2.7 & -2.4 \\
\hline LOC283267 & Long intergenic non-protein coding RNA 294 & NR_015451.1 & -4.3 & -2.6 & -2.6 \\
\hline CCNB1 & Cyclin B1 & NM_031966.2 & -4.3 & -2.4 & -2.2 \\
\hline YAP1 & Yes-associated protein 1 & NM_006106.2 & -4.3 & -2.0 & -2.5 \\
\hline XPO1 & Exportin 1 (CRM1 homolog, yeast) & NM_003400.3 & -4.4 & -2.9 & -2.6 \\
\hline PTPN11 & Protein tyrosine phosphatase, non-receptor type 11 & NM_002834.3 & -4.4 & -2.4 & -2.5 \\
\hline PHF3 & PHD finger protein 3 & NM_015153.1 & -4.4 & -2.2 & -2.6 \\
\hline VMA21 & Vacuolar H+-ATPase homolog (S. cerevisiae) & NM_001017980.2 & -4.4 & -2.2 & -2.3 \\
\hline CHST15 & Carbohydrate sulfotransferase 15 & NM_015892.2 & -4.4 & -2.0 & -2.5 \\
\hline RUNX2 & Runt-related transcription factor 2 & NM_001024630.2 & -4.5 & -2.7 & -2.4 \\
\hline KIF14 & Kinesin family member 14 & NM_014875.1 & -4.6 & -3.4 & -2.2 \\
\hline EHBP1 & EH domain binding protein 1 & NM_015252.2 & -4.6 & -2.7 & -2.6 \\
\hline NEK2 & NIMA-related kinase 2 & NM_002497.2 & -4.6 & -2.7 & -2.6 \\
\hline STK38 & Serine/threonine kinase 38 & NM_007271.2 & -4.7 & -3.2 & -2.4 \\
\hline ZNF22 & Zinc finger protein 22 & NM_006963.3 & -4.7 & -3.2 & -2.8 \\
\hline SPRY4 & Sprouty homolog 4 (Drosophila) & NM_030964.2 & -4.7 & -2.0 & -2.1 \\
\hline GMFB & Glia maturation factor, beta & NM_004124.2 & -4.8 & -2.2 & -3.2 \\
\hline GCNT1 & Glucosaminyl (N-acetyl) transferase 1, core 2 & NM_001097635.1 & -4.8 & -3.1 & -2.4 \\
\hline HERC4 & $\begin{array}{c}\text { HECT and RLD domain containing E3 ubiquitin } \\
\text { protein ligase } 4\end{array}$ & NM_022079.2 & -4.8 & -3.1 & -2.6 \\
\hline PPP4R1 & Protein phosphatase 4, regulatory subunit 1 & NM_005134.2 & -4.8 & -2.1 & -2.6 \\
\hline SMAD5 & SMAD family member 5 & NM_005903.5 & -4.9 & -2.2 & -3.2 \\
\hline GNG12 & guanine nucleotide binding protein (G protein), gamma 12 & NM_018841.4 & -4.9 & -2.8 & -2.1 \\
\hline SMARCA1 & $\begin{array}{l}\text { SWI/SNF related, matrix associated, actin dependent } \\
\text { regulator of chromatin, subfamily a, member } 1\end{array}$ & NM_003069.2 & -4.9 & -2.8 & -2.3 \\
\hline DEK & DEK oncogene & NM_003472.2 & -4.9 & -2.5 & -2.4 \\
\hline FAM107B & Family with sequence similarity 107 , member B & NM_031453.2 & -5.1 & -3.1 & -2.1 \\
\hline SUZ12 & Suppressor of zeste 12 homolog (Drosophila) & NM_015355.1 & -5.1 & -2.8 & -2.7 \\
\hline OSBPL3 & Oxysterol binding protein-like 3 & NM_145322.1 & -5.1 & -2.7 & -2.7 \\
\hline UBE3C & Ubiquitin protein ligase E3C & NM_014671.1 & -5.1 & -2.7 & -2.7 \\
\hline HSDL2 & Hydroxysteroid dehydrogenase like 2 & NM_032303.3 & -5.1 & -2.5 & -2.5 \\
\hline C14orf106 & MIS18 binding protein 1 & NM_018353.3 & -5.1 & -2.3 & -2.3 \\
\hline MBP & Myelin basic protein & NM_001025100.1 & -5.1 & -2.0 & -2.3 \\
\hline GPAM & Glycerol-3-phosphate acyltransferase, mitochondrial & NM_020918.3 & -5.2 & -3.1 & -2.7 \\
\hline RASA1 & RAS p21 protein activator (GTPase activating protein) 1 & NM_002890.1 & -5.2 & -2.9 & -3.1 \\
\hline KIF11 & Kinesin family member 11 & NM_004523.2 & -5.2 & -3.3 & -3.1 \\
\hline FBXO5 & F-box protein 5 & NM_012177.2 & -5.2 & -3.1 & -2.3 \\
\hline CENPE & Centromere protein E, $312 \mathrm{kDa}$ & NM_001813.2 & -5.2 & -2.6 & -2.3 \\
\hline PAK2 & p21 protein (Cdc42/Rac)-activated kinase 2 & NM_002577.3 & -5.3 & -3.3 & -3.6 \\
\hline IL7R & Interleukin 7 receptor & XM_937367.1 & -5.3 & -2.8 & -2.2 \\
\hline ENC1 & Ectodermal-neural cortex 1 (with BTB domain) & NM_003633.1 & -5.3 & -2.6 & -2.3 \\
\hline SOX9 & SRY (sex determining region Y)-box 9 & NM_000346.2 & -5.3 & -2.5 & -2.3 \\
\hline ASXL1 & Additional sex combs like 1 (Drosophila) (ASXL1), TV1 & NM_015338.4 & -5.3 & -2.0 & -2.0 \\
\hline C10orf6 & Family with sequence similarity 178 , member $\mathrm{A}$ & NM_018121.2 & -5.5 & -3.2 & -3.4 \\
\hline CEP55 & Centrosomal protein 55 kDa & NM_018131.3 & -5.6 & -3.4 & -2.6 \\
\hline
\end{tabular}


Table 3 List of genes that statistically distinguish the hyperthermic response of three breast cancer lines from the mammary epithelial cells in the $\boldsymbol{H}^{\prime}$ vs $\boldsymbol{H}$ analysis (Continued)

\begin{tabular}{|c|c|c|c|c|c|}
\hline NMT2 & N-myristoyltransferase 2 & NM_004808.2 & -5.6 & -2.4 & -2.0 \\
\hline PPPDE1 & Desumoylating isopeptidase 2 & NM_016076.3 & -5.8 & -2.4 & -2.9 \\
\hline TGFBR2 & Transforming growth factor, beta receptor II (70/80 kDa) & NM_001024847.1 & -6.0 & -2.1 & -2.2 \\
\hline MID1 & Midline 1 (Opitz/BBB syndrome) & NM_033290.2 & -6.2 & -2.9 & -2.1 \\
\hline FNDC3B & Fibronectin type III domain containing 3B & NM_001135095.1 & -6.2 & -2.8 & -2.6 \\
\hline $\mathrm{BIRC2}$ & Baculoviral IAP repeat containing 2 & NM_001166.3 & -6.2 & -2.9 & -2.7 \\
\hline FAM3C & Family with sequence similarity 3 , member $C$ & NM_001040020.1 & -6.2 & -2.4 & -2.0 \\
\hline KIF23 & Kinesin family member 23 & NM_004856.4 & -6.3 & -3.4 & -2.7 \\
\hline CLIC4 & Chloride intracellular channel 4 & NM_013943.1 & -6.3 & -3.4 & -2.6 \\
\hline PDGFC & Platelet derived growth factor $C$ & NM_016205.1 & -6.4 & -2.4 & -2.0 \\
\hline PRKCA & Protein kinase C, alpha & NM_002737.2 & -6.7 & -2.5 & -2.2 \\
\hline NCAPG & Non-SMC condensin I complex, subunit G & NM_022346.3 & -7.1 & -2.6 & -2.1 \\
\hline CENPF & Centromere protein F, 350/400 kDa & NM_016343.3 & -7.4 & -2.9 & -2.7 \\
\hline GCNT2 & $\begin{array}{l}\text { Glucosaminyl (N-acetyl) transferase 2, } \\
\text { l-branching enzyme (I blood group) }\end{array}$ & NM_001491.2 & -7.4 & -2.5 & -2.5 \\
\hline C14orf135 & Pecanex-like 4 (Drosophila) & NM_022495.5 & -7.5 & -2.7 & -2.5 \\
\hline PBK & PDZ binding kinase & NM_018492.2 & -7.8 & -3.3 & -2.4 \\
\hline TOP2A & Topoisomerase (DNA) II alpha 170 kDa & NM_001067.2 & -8.1 & -3.8 & -2.7 \\
\hline CAV2 & Caveolin 2 & NM_001233.3 & -8.1 & -2.3 & -2.5 \\
\hline SERTAD2 & SERTA domain containing 2 & NM_014755.1 & -8.3 & -3.1 & -3.6 \\
\hline ACSL4 & Acyl-CoA synthetase long-chain family member 4 & NM_004458.1 & -8.5 & -2.5 & -2.5 \\
\hline FAM83D & Family with sequence similarity 83, member $D$ & NM_030919.2 & -9.2 & -4.3 & -3.8 \\
\hline CDK6 & Cyclin-dependent kinase 6 & NM_001259.5 & -9.4 & -3.1 & -4.1 \\
\hline FRMD6 & FERM domain containing 6 & NM_152330.3 & -9.5 & -3.1 & -2.4 \\
\hline SNAPC1 & Small nuclear RNA activating complex, polypeptide 1, 43 kDa & NM_003082.2 & -9.8 & -2.3 & -2.0 \\
\hline CALD1 & Caldesmon 1 & NM_033140.2 & -9.9 & -2.1 & -2.5 \\
\hline BCAT1 & Branched chain amino-acid transaminase 1, cytosolic & NM_005504.4 & -10.2 & -5.6 & -4.2 \\
\hline DLGAP5 & Discs, large (Drosophila) homolog-associated protein 5 & NM_014750.3 & -10.4 & -3.1 & -2.4 \\
\hline ANLN & Anillin, actin binding protein & NM_018685.2 & -10.9 & -3.1 & -2.2 \\
\hline TACC1 & Transforming, acidic coiled-coil containing protein 1 & NM_006283.1 & -11.1 & -2.7 & -2.6 \\
\hline AP1S2 & Adaptor-related protein complex 1, sigma 2 subunit & NM_003916.3 & -11.5 & -2.5 & -2.1 \\
\hline CTNNAL1 & Catenin (cadherin-associated protein), alpha-like 1 & NM_003798.2 & -13.9 & -3.1 & -2.1 \\
\hline DCBLD2 & Discoidin, CUB and LCCL domain containing 2 & NM_080927.3 & -14.5 & -3.1 & -2.6 \\
\hline CAV1 & Caveolin 1, caveolae protein, 22 kDa & NM_001753.3 & -20.1 & -3.3 & -2.8 \\
\hline
\end{tabular}

hyperthermia, revealing that while many gene expression changes were common between one or more of the breast cancer lines, not a single 2-fold or greater gene expression change was shared between the mammary epithelial line and all three breast cancer lines (Figure 1B). This data strongly suggested that the hyperthermic response of breast cancer cells is truly distinct from that of mammary epithelial cells. As an independent assessment, we generated profile plots depicting the changes in normalized intensity values between the four cell lines, revealing that many of the statistically significant gene expression alterations we identified were largely shared between the three breast cancer lines and distinctly unique from that of the MCF10A line (Figure 1C). Using Metacore network analysis of the microarray data, we identified key signaling pathways that were unique to the mammary epithelial line and the three breast cancer lines. The hyperthermic response of MFC10A was strongly indicative of statistically significant gene expression alterations in a large number of genes involved in cell cycle regulation, apoptosis, heat shock response, and DNA damage response, (Figure 2A-D, Table 2) and 
changes in the expression of genes involved in these biological pathways were not observed in the three breast cancer lines. Network analysis indicated that signaling pathways with the highest statistical significance amongst the three breast cancer lines responding to hyperthermia (but not in the MCF10A line) included genes involved in Ras and Rab5A G-protein regulation (GAPVD1, RASA1, RABEP1, CALM1, GMFB, PTPN11)
(Figure 2E, Table 2) and survival/apoptosis (MAP2K4, BIRC2) (Figure 2B, Table 2).

Identification of hyperthermia induced genes that differentiate the heat shock response of mammary epithelial cells from that of breast cancer cells

Our previous analysis compared the hyperthermic response of each individual cell line to its transcriptional expression

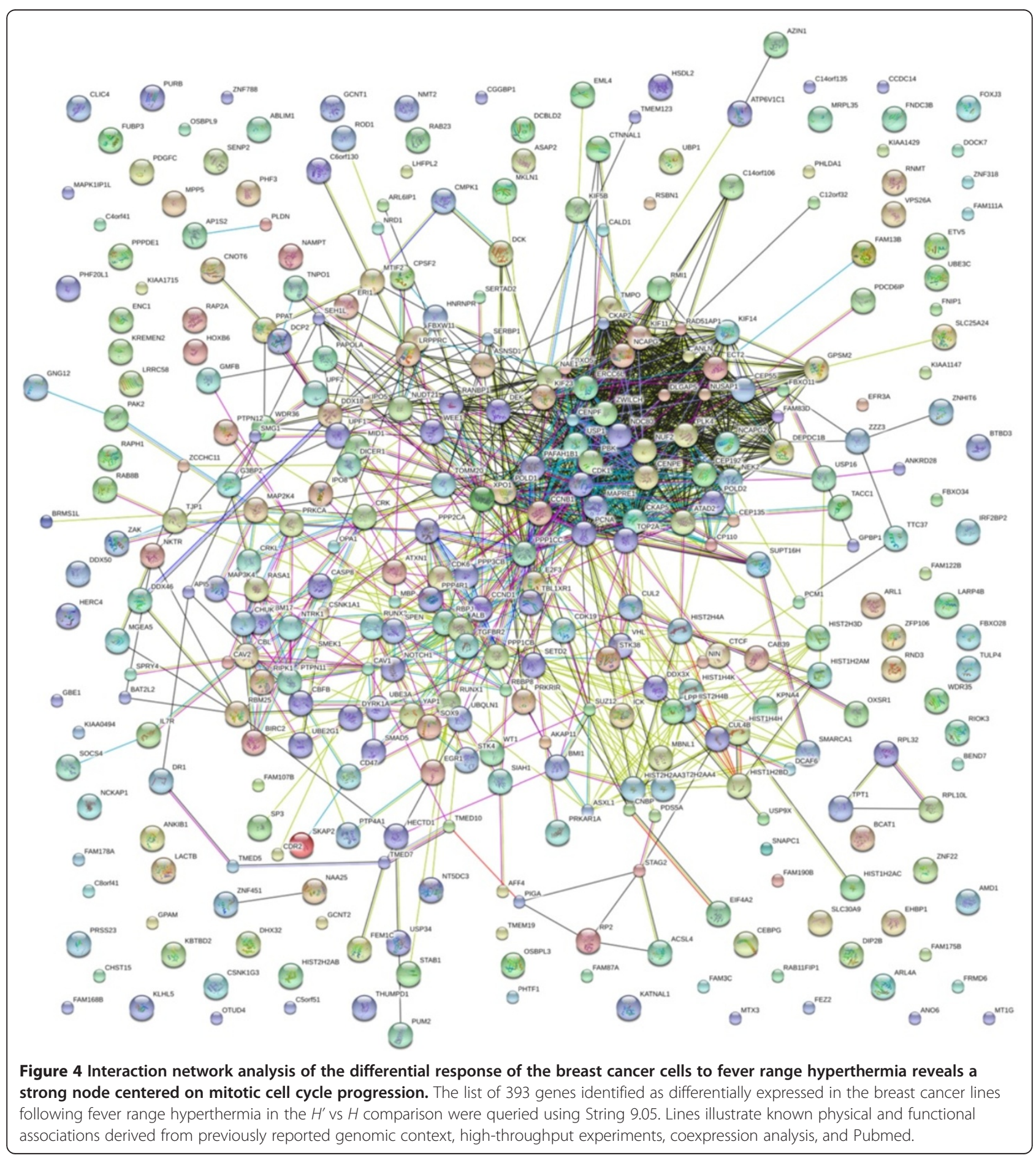


baseline at the normal growth temperature ( $C$ vs $H$ and $C^{\prime}$ vs $H^{\prime}$ ). Though this analysis provides us with information on how each individual cell line responds to hyperthermia relative to its normal growth temperature, it does not provide absolute comparisons of the transcriptome response of breast cancer cells relative to mammary epithelial cells following the elevated temperature. To better understand what provides breast cancer cells the selective disadvantage over mammary epithelial cells in response to hyperthermia we must identify those genes that are differentially expressed in breast cancer cell lines following hyperthermia from those of the mammary epithelial cell line following hyperthermia. To perform this analysis, we directly compared the gene expression changes that occurred for $H^{\prime}$ vs $H$ and identified genes whose expression was truly distinct between the breast cancer and mammary epithelial cell lines following hyperthermia.

When comparing $H^{\prime}$ (MCF7) vs $H$ we identified 2708 genes whose expression was distinct at statistically significant levels ( $\geq 2$ fold, $\mathrm{p}<0.05)$. $H^{\prime}$ vs $H$ comparisons of the MDA231 and MDA468 lines yielded 919 and 750 significant gene expression changes, respectively. Heatmap analysis indicated a strong trend in the gene expression profiles between each of the three breast cancer lines following hyperthermia (Figure 3A). Using a Venn diagram that strictly eliminated any genes with less than a 2 -fold expression change $(\mathrm{p}<0.05)$, we compared the gene expression alterations that were uniquely shared between all three cancer lines $\left(H^{\prime}\right)$ relative to the mammary epithelial line $(H)$ (Figure $3 \mathrm{~B})$. This interpretation uncovered 393 genes whose 2 -fold or greater changes in gene expression were differentially expressed in common amongst the three breast cancer lines following mild hyperthermic shock when compared to MCF10A cells following the same treatment (Table 3). These are the core genes that differentiate the hyperthermic response of breast cancer cells from that of mammary epithelial cells. In these data potentially lay the mechanism that may help define how mild hyperthermia preferentially selects against tumor cells.

We performed computational analysis on the 393 genes using String software to identify interaction networks that might help reveal functional nodes indicative of the biological response of these cells to fever range hyperthermia. Our analysis uncovered a remarkably dense interaction node centered on genes involved in mitotic progression (Figure 4). We performed Metacore analysis on the list of 393 genes, confirming that mitotic cell cycle regulatory networks exclusively dominated the top statistically significant pathway maps (Table 4 lists the top 20 identified networks). Figure 5 illustrates Metacore's analysis of the interrelationships of the identified mitotic regulatory genes including STAG2, NEK2, KPNA4, IPO5, TNPO1, CCNB1, CDK1, CDK6, NCAPG, NCAPG2, TOP2A, NUF2, CENPE,
Table 4 Top 20 significantly significant GeneGo pathway maps that are differentially expressed amongst all three breast cancer cell lines relative to the mammary epithelial line in the $\boldsymbol{H}^{\prime}$ vs $\boldsymbol{H}$ comparison

\begin{tabular}{ll}
\hline GeneGo Pathway & $\mathbf{p}$-Value \\
\hline Mitosis & $8.15 e^{-44}$ \\
Cell division & $3.02 e^{-35}$ \\
Cell cycle & $5.37 e^{-23}$ \\
Mitotic sister chromatid segregation & $1.31 e^{-22}$ \\
Mitotic spindle organization & $4.87 e^{-20}$ \\
Protein localization to kinetochore & $1.54 e^{-19}$ \\
Chromosome segregation & $4.85 e^{-16}$ \\
Establishment of mitotic spindle orientation & $7.53 e^{-16}$ \\
Mitotic cell cycle & $9.66 e^{-16}$ \\
Homologous chromosome segregation & $3.30 e^{-13}$ \\
Mitotic cell cycle checkpoint & $5.99 e^{-12}$ \\
Anaphase promoting complex-dependent degradation & $2.27 e^{-10}$ \\
Mitotic cell cycle spindle assembly checkpoint & $2.03 e^{-09}$ \\
Spindle assembly involved in mitosis & $4.44 e^{-09}$ \\
Mitotic anaphase & $6.97 e^{-09}$ \\
Microtubule-based movement & $3.57 e^{-08}$ \\
Spindle organization & $4.83 e^{-08}$ \\
Mitotic centrosome separation & $7.75 e^{-08}$ \\
Spindle assembly & $1.92 e^{-07}$ \\
\hline
\end{tabular}

CENPF, ZWILCH, PDS5A, WEE1, KIF11, CHUK, and $P P P 1 C B$. Of the 393 genes that were differentially expressed between the breast cancer and mammary epithelial cells following $H^{\prime}$ to $H$ analysis, approximately $80 \%$ of the top 60 most upregulated genes were histone clusters and non-protein coding RNAs such as small nucleolar-, ribosomal-, and micro-RNAs. These data cumulatively suggest that the selective disadvantage that breast cancer lines experience following mild hyperthermic shock may be due to an inability to correctly regulate their core biological processes and mitotic cell cycle machinery. The differential expression of genes involved in these processes for the $H^{\prime}$ vs $H$ analysis is shown in Figure 6.

\section{Altered expression of mitotic arrest genes differentiates the hyperthermic response of breast cancer cells from that of mammary epithelial cells}

Our microarray analysis strongly suggests that the inability of breast cancer cells to regulate their mitotic cell cycle machinery may be a major contributing factor to their selective disadvantage following hyperthermia. Therefore we independently tested the expression levels of a panel of mitotic regulators that were identified as differentially expressed in the $H^{\prime}$ vs $H$ analysis. Quantitative real time PCR analysis of cDNA collected from the $H^{\prime}$ vs $H$ 


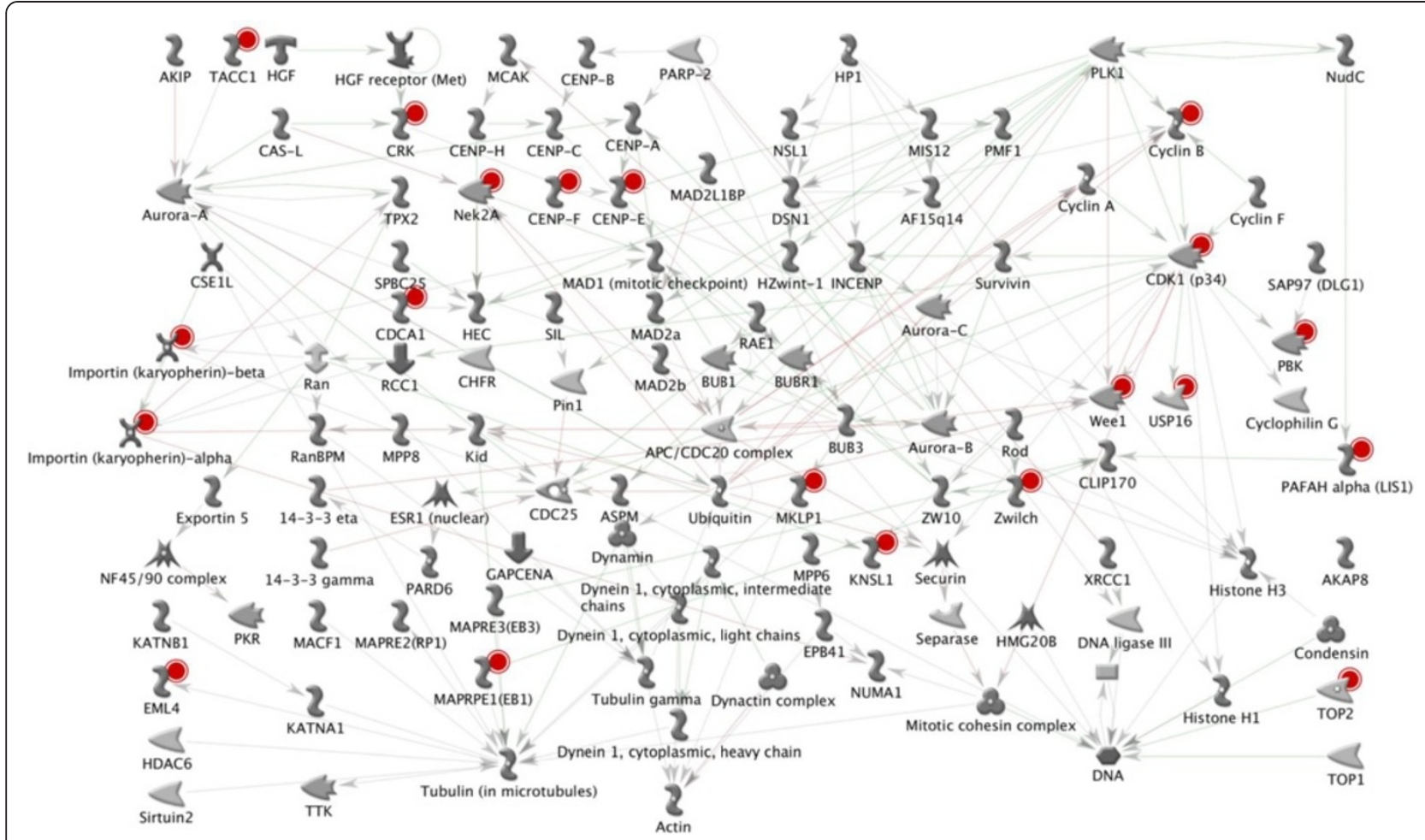

Figure 5 Interrelationship between the mitotic regulators that differentiate the hyperthermic response of breast cancer cells from mammary epithelial cells. Metacore analysis of the 393 genes that differentiate the hyperthermic response of breast cancer from mammary epithelial cells in the $H^{\prime}$ vs $H$ comparison identified mitotic cell cycle progression (and 20 associated mitotic regulatory genes) as the primary differential gene networks. We used Metacore to identify the interrelationship of the known physical and functional associations between these 20 genes (red markers).

treatments for the steady state mRNA levels of several genes with core processes related to mitosis including KIF11, CDK6, STAG2, NEK2, CHUK, KPNA4, CENPF, and NCAPG correlated well with our microarray data, revealing differential expression of these genes for each cell line in the hyperthermia treatment relative to the normal temperature (Figure 7A). A comparison of the qPCR and microarray data for each of these selected genes for the H' to $\mathrm{H}$ comparisons is depicted in Table 5. To confirm the hyperthermia-induced mitotic defect in the breast cancer lines, we subjected all four cell lines to 30 minutes of fever range hyperthermia $\left(H\right.$ and $\left.H^{\prime}\right)$ or normal control temperature $\left(C\right.$ and $\left.C^{\prime}\right)$ and collected the cells after 24 hours for cell cycle analysis using flow cytometry. The cells were collected $24 \mathrm{hrs}$ after treatment as this is sufficient time to see the phenotypic effects on the cell cycle that would be induced by altered RNA expression. Propidium iodide staining of cells from each condition clearly revealed that a $\mathrm{G} 2 / \mathrm{M}$ phase accumulation as a common event across all three breast cancer lines following hyperthermia even after 24 hours following the treatment, but did not occur in the mammary epithelial lines (Figure 7B). Collectively, these data provide evidence to suggest that the selective disadvantage of breast cancer cells in response to hyperthermia could be due, in part, to altered regulation of mitotic machinery following heat shock.

\section{Discussion}

While hyperthermic treatment of tumors has been utilized since the time of the ancient Greeks and modern medicine has implemented hyperthermia as an adjuvant treatment in various settings, use of this technique has been marred with limitations including the inability to target heat to the tumor without collateral damage to the neighboring cells, homogenous heat dispersion throughout the entire tumor, and intrinsic problems with targeting undetectable micrometastases. In recent years, advances in nanoparticle-enabled thermal therapy hold the promise to overcome many of these issues, thus a strong interest in treatment of tumors with hyperthermia has been renewed. While it has been established for decades that normal tissues exhibit enhanced thermotolerance relative to cancer cells $[1,2]$, the mechanisms controlling this are largely unknown. Studies on the heat shock response of cancer cells have revealed changes in apoptosis, cell cycle regulation, and cell structure/maintenance [3], yet very little has been reported critically comparing the heat shock responses of 


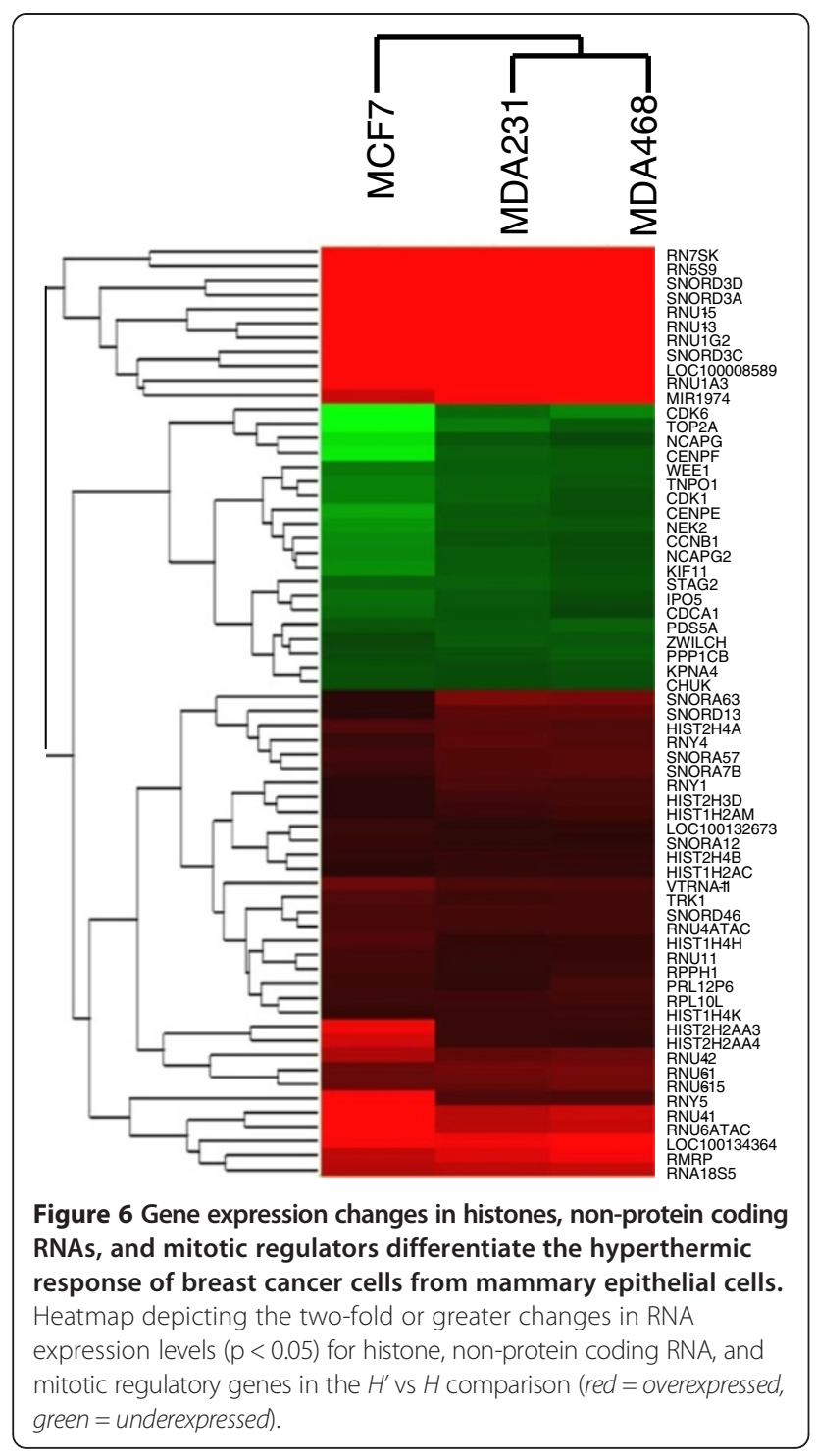

cancer cells to their non-diseased cellular counterparts. Thus it is currently unknown at the molecular level how thermotolerance is maintained in normal cells, but lost or deregulated in cancer cells. To address this, we utilized a genomics approach to address two areas: 1) identify the global transcriptional response to hyperthermia of a panel of breast cancer and mammary epithelial cells using a $C$ vs $H$ and $C^{\prime}$ vs $H^{\prime}$ analysis and 2) compare the hyperthermiainduced changes in global gene expression patterns of the breast cancer cell lines to the mammary epithelial cells using a $H^{\prime}$ vs $H$ analysis. As a result of these studies, we identified several gene networks that reflect the hyperthermic response of breast cancer and mammary epithelial cells (including cell cycle, heat shock, survival/apoptosis, DNA damage and Rab/Ran regulation) and that clearly differentiate the response of breast cancer cells from that of mammary epithelial cells (including mitotic regulation and expression of histone and non-protein coding RNAs).

\section{Evaluation of the hyperthermic response of breast cancer and mammary epithelial cells}

$C$ vs $H$ and $C^{\prime}$ vs $H^{\prime}$ comparative analysis of the gene expression profiles of each cell line revealed that the mammary epithelial cells responded to increased temperature distinctly from the breast cancer lines, with altered regulation of gene networks controlling DNA damage response, cell cycle progression, apoptosis, and heat shock characterizing the mammary epithelial cell response. In contrast, the three breast cancer lines commonly altered gene networks encoding Rab and Ran G-protein regulators in response to hyperthermia.

Arguably the most studied response of cells to hyperthermia is that of heat shock protein activation and expression and one might guess that heatshock-protein mediated responses are likely responsible for the selective disadvantage of solid tumors to fever range hyperthermia. Numerous cell stresses have been shown to induce heat shock proteins, which act as molecular chaperones inside cells to modulate thermotolerance and protect cells from stress-induced death [27-29]. MCF10A cells exhibited significantly increased expression of HSP90AA1, CARHSP1, HSPA12A and decreased expression of HSPB1, HSPBL2, HSPA6, and HSPA7 ( $C$ vs $H$ ), while the three breast cancer lines showed no significant 2-fold or greater alterations in the expression of these genes $\left(C^{\prime}\right.$ vs $\left.H^{\prime}\right)$. Despite this finding, we provide evidence that suggests the ability of mammary epithelial cells to properly modulate their heat shock response does not contribute to the selective disadvantage of breast cancer cells to hyperthermia. For instance, comparison of heat shock protein expression in the $H^{\prime}$ vs $H$ analysis revealed no significant difference in the relative abundance of these heat shock protein genes regardless of the cell type. As elevated expression of heat shock proteins has been observed in various types of cancers [30-32], hyperthermic shock may simply bring the heat shock protein expression in MCF10A cells to the baseline levels in the breast cancer lines.

Hyperthermia has long been known as an effective radio- and chemo-sensitizing agent and it would be an attractive hypothesis that hyperthermia may impart a selective disadvantage to breast cancer cells via upregulation of DNA damage or reduction in its repair. Indeed, hyperthermia has been shown to induce chromosomal damage during S-phase [33] and inhibit homologous recombination repair via a heat shock protein/Brca1/2 pathway [34-36]. Furthermore, hyperthermia induces signaling pathways that overlap with those activated by ionizing radiation-induced DNA damage including histone H2Ax phosphorylation and enhanced ataxia-telangiectasia mutated protein (ATM) activity [37]. Analysis of $C$ vs $H$ 


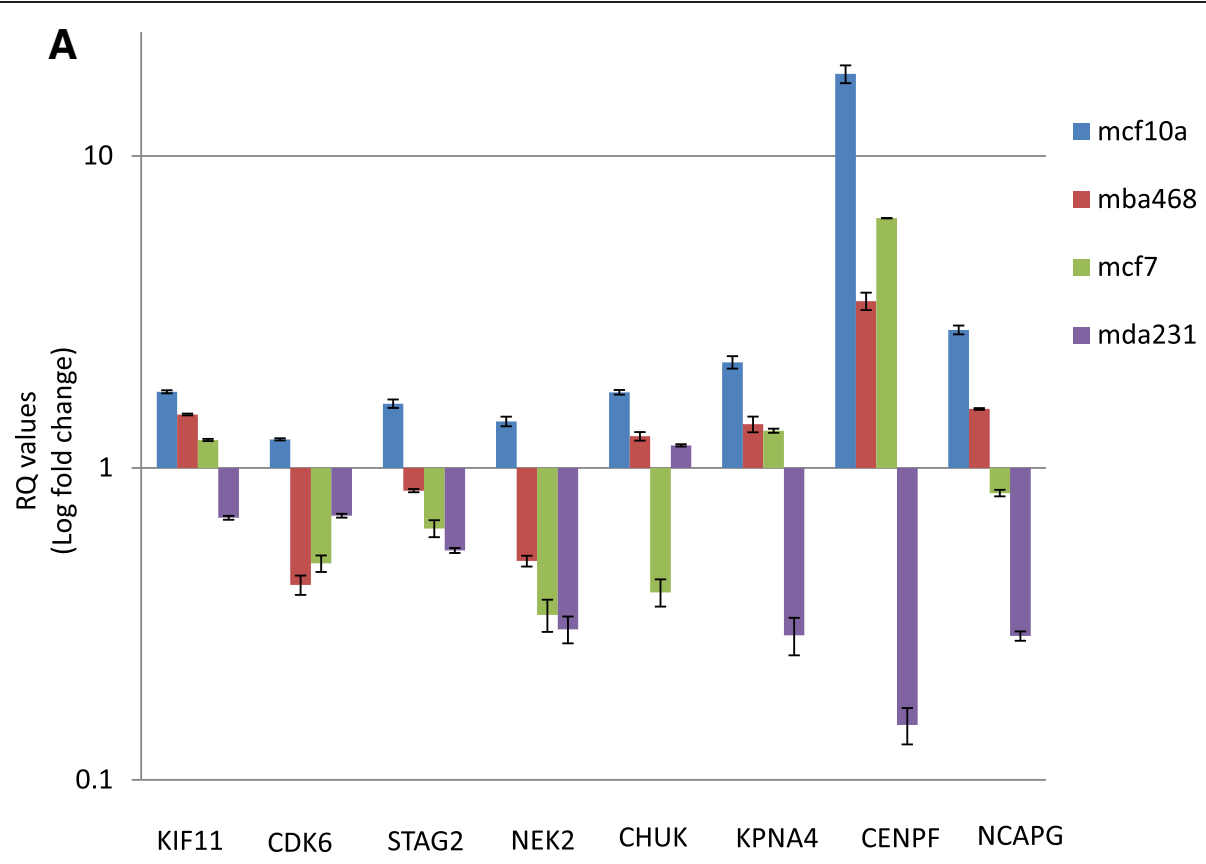

B

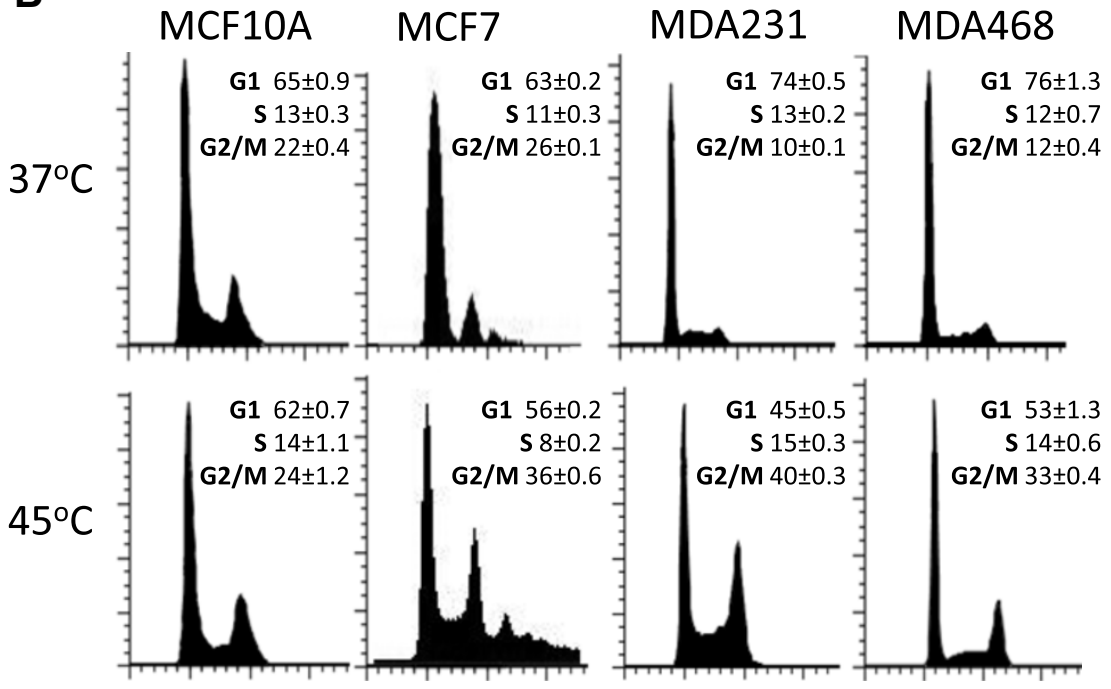

Figure 7 Biological confirmation of gene expression analysis. (A) qPCR analysis measuring the fold change of mitotic regulators following hyperthermia treatment. RQ values are represented as the hyperthermia-induced change in gene expression for each gene relative to the expression of the same gene in the normal temperature condition $(\mathrm{RQ}=1)$. The data shown are the median of at least 3 replicates, plus or minus the standard deviation, and presented in log scale. (B) The panel of mammary epithelial and breast cancer cells were grown under standard growth conditions or treated with 30 minutes fever range hyperthermic shock. Cells were harvested after 24 hours and cell cycle analysis was performed using flow cytometric detection of propidium iodide intensity.

and $C^{\prime}$ vs $H^{\prime}$ revealed a number of genes involved in DNA damage response whose expression was altered in the MCF10A cells, and similar changes were not observed in the three breast cancer lines. Despite this, no statistically significant changes in gene expression for these genes were observed in our $H^{\prime}$ vs $H$ comparison, suggesting that (similar to the heat shock proteins) this pathway may not clearly distinguish the selective disadvantage of breast cancer cells to hyperthermia.

Gene networks that distinguish the hyperthermic response of breast cancer cells from mammary epithelial cells

As our initial analysis compared only the heat shock response of each individual cell line relative to its 


\begin{tabular}{|c|c|c|c|c|c|c|}
\hline \multirow[t]{2}{*}{ Gene Symbol } & \multicolumn{2}{|c|}{ MCF7 } & \multicolumn{2}{|c|}{ MBA231 } & \multicolumn{2}{|c|}{ MBA468 } \\
\hline & qPCR & Array & qPCR & Array & qPCR & Array \\
\hline KIF11 & -1.5 & -5.2 & -2.6 & -3.3 & -1.2 & -3.1 \\
\hline CDK6 & -2.4 & -9.4 & -1.7 & -3.1 & -3.0 & -4.1 \\
\hline STAG2 & -2.7 & -3.0 & -3.2 & -2.9 & -2.0 & -2.5 \\
\hline NEK2 & -4.7 & -4.6 & -1.7 & -2.7 & -2.8 & -2.6 \\
\hline CHUK & -4.3 & -2.3 & -1.4 & -2.2 & -1.3 & -2.3 \\
\hline KPNA4 & -1.7 & -2.4 & -7.3 & -2.2 & -1.6 & -2.4 \\
\hline CENPF & -2.9 & -7.4 & -183 & -2.9 & -5.4 & -2.7 \\
\hline NCAPG & -3.5 & -4.2 & -9.3 & -2.7 & -1.9 & -2.2 \\
\hline
\end{tabular}

$\mathrm{p} \leq 0.05$ for all values via Student's t-test.

transcriptional expression at normal growth temperature, we extended our analysis by directly comparing the transcriptional response of the $H^{\prime}$ vs $H$ treatments to identify the unique gene networks that clearly differentiate the gene expression changes unique to the breast cancer cells following heat treatment. This comparative analysis identified cell cycle networks preferentially involved in mitotic progression as well as large scale changes in the expression of histones and non-protein coding RNAs as the major distinctions between the hyperthermic responses between the breast cancer lines and the MCF10A cells. $80 \%$ of the top 60 genes commonly expressed at higher levels in the three breast cancer lines following heat shock relative to the mammary epithelial line following heat shock were histones and non-coding RNA. This effect was due primarily to decreased expression of these genes in the MCF10A cells with no change or only a small upregulation in expression in the breast cancer lines, suggesting that mammary epithelial cells are repressing many of their core processes (chromatin condensation, transcription, translation, etc.) following hyperthermic shock, while the breast cancer cells may continue performing these processes as normal. Similar findings have been reported following other cellular stresses whereby oxidative damage significantly decreases the expression of histones and ribosomal proteins [38]. In addition to histone gene expression, heat shock induces an array of chromatin post-translational modifications. For instance, HSP70 has been shown to enhance the phosphorylation of histone $\mathrm{H} 3$ following heat shock [39], and histone variant H3.3 has been shown to stimulate heat shock induced HSP70 transcription [40], suggesting that heat shock response and histone activity are tightly regulated.

Our data revealed that a number of small nucleolar RNAs, which play key roles in ribosomal biosynthesis, were differentially regulated between the mammary epithelial and breast cancer cells following hyperthermia. Several small nucleolar RNAs are reportedly critical mediators of oxidative stress and their overexpression has been associated with reduced resistance to oxidative stress $[41,42]$. Small nucleolar RNAs have been shown to bind to the mature RNA of heat shock cognate protein (HSC70) [43] and inhibition of Hsp90 prevents the accumulation of U3 and U4 small nuclear ribonucleoproteins via a process that involves Pih1/Nop17 and R2Tp complexes [44-46].

Changes in cell cycle progression (particularly mitotic catastrophe) have been repeatedly shown to characterize the hyperthermic response of numerous cell types [47-49], though it is largely unstudied as to how cell cycle changes differ between normal and tumor cell lines following this treatment. Major distinctions in cell cycle networks involved in mitotic progression clearly distinguished the $H^{\prime}$ vs $H$ analysis of our data. The genes that were differentially expressed at statistically significant levels included those involved in spindle assembly and chromosome separation, chromosome condensation in prometaphase, metaphase checkpoint, sister chromatid cohesion, and initiation of mitosis. Our confirmatory experiments using flow cytometry further revealed that hyperthermia treated breast cancer cells stalled in the G2/M phase of the cell cycle within 24 hours posttreatment, while the cell cycle profiles of heat-shocked mammary epithelial cells were similar to those grown at normal temperatures. Interestingly, it has been shown that cells vary in their susceptibility to heat in accordance to their phase in the cell cycle, with the highest heat sensitivity observed during mitosis due to damage to the mitotic apparatus, leading to inefficient mitosis and polyploidy. M- and S-phase arrested cells show increased susceptibility to heat-induced damage, while G1-phase cells are relatively heat resistance [50-53].

This study has been the first to shed light on the comparisons of transcriptome-level fever range hyperthermic responses of mammary epithelial cells to breast cancer cells. While this data points to a number of areas that potentially contribute to the selective advantage of normal breast epithelium over its malignant counterparts following hyperthermia, our studies were simplistic in that they utilized a cell culture monolayer system solely consisting of cells derived from normal or tumor breast tissue. We have gained solid insight into the responses of these particular cell types to fever range hyperthermia, however a tumor is a very complex entity. For instance, solid tumors are not only composed of the tumor cells, but also consist of endothelial, fibroblast, and immune cells which will each respond to hyperthermia in their own fashion and potentially affect the response of the tumor as a whole. Moreover, heterogenous heat distribution and dissipation due to a faulty tumor vascular system may induce uneven heating in the tumor itself, thus affecting some areas distinctly and differentially altering the tumor's response to 
hyperthermia. Future studies should be undertaken to address these issues.

\section{Conclusion}

Collectively, our data suggest that fever range hyperthermia affects breast cancer cells distinctly from mammary epithelial cells. These differences are largely attributed to alterations in the expression of genes involved in mitotic cell cycle progression, histones, and non-coding RNAs. Considering the hyperthermia induced G2/M cell cycle defects observed in the breast cancer cells but not the mammary epithelial cells, these data pose the question as to whether hyperthermia may function in a synergistic manner when combined with drugs that specifically target mitosis such as taxols and vinca alkaloid derivatives.

\section{Abbreviations}

$\mathrm{C}: 37^{\circ} \mathrm{C}$ treatment of mammary epithelial cells; $\mathrm{C}^{\prime}: 37^{\circ} \mathrm{C}$ of breast cancer cells; $\mathrm{H}: 45^{\circ} \mathrm{C}$ of mammary epithelial cells; $\mathrm{H}^{\prime}: 45^{\circ} \mathrm{C}$ of breast cancer cells; RNA: Ribonucleic acid; DNA: Deoxyribonucleic acid; aRNA: Amplified RNA; cDNA: Complementary DNA; mRNA: Messenger RNA; G1: Gap 1; S: Synthesis; G2: Gap 2; M: Mitosis; RT PCR: Real time polymerase chain reaction.

\section{Competing interests}

The authors declare that they have no competing interests.

\section{Authors' contributions}

CA contributed to experimental concept and design, cultured and treated cells, purified RNA, performed analysis and interpretation of microarray data, carried out network analysis, drafted and revised manuscript, gave final approval for version to be published. VK contributed to interpretation of network analysis, assisted with drafting and revising manuscript, gave final approval for version to be published. JS cultured and treated cells, purified RNA, drafting and revising manuscript, gave final approval for version to be published. AN performed flow cytometric cell cycle analysis and interpretation of data, gave final approval for version to be published. AA cultured cells, gave final approval for version to be published. RL contributed to experimental concept and design, drafted and revised manuscript, gave final approval for version to be published. CB contributed to concept and design, drafted and revised manuscript, gave final approval for version to be published. DM performed microarray experiments, performed bioinformatics analysis and interpretation of data, drafted and revised manuscript, gave final approval for version to be published. BB contributed to concept and design, acquisition of data, analysis and interpretation of data, drafted and revised manuscript, gave final approval for version to be published.

\section{Acknowledgements}

This research was supported by startup funding to BB from TTUHSC.

\section{Author details}

${ }^{1}$ Department of Biomedical Sciences, Paul L. Foster School of Medicine, Texas Tech University Health Sciences Center, 5001 El Paso Drive, MSB1 Room 2111, El Paso, Texas 79905, USA. ²Department of Physics, University of Texas, El Paso, Texas, USA.

Received: 31 July 2013 Accepted: 22 January 2014

Published: 11 February 2014

\section{References}

1. Habash RW, Bansal R, Krewski D, Alhafid HT: Thermal therapy, part 2: hyperthermia techniques. Crit Rev Biomed Eng 2006, 34(6):491-542.

2. Habash RW, Bansal R, Krewski D, Alhafid HT: Thermal therapy, part 1: an introduction to thermal therapy. Crit Rev Biomed Eng 2006, 34(6):459-489.

3. Horsman MR, Overgaard J: Hyperthermia: a potent enhancer of radiotherapy. Clin Oncol (R Coll Radiol) 2007, 19(6):418-426.

4. van der Zee J: Heating the patient: a promising approach? Ann Oncol 2002, 13(8):1173-1184.
5. Wust P, Hildebrandt B, Sreenivasa G, Rau B, Gellermann J, Riess H, Felix R, Schlag PM: Hyperthermia in combined treatment of cancer. Lancet Oncol 2002, 3(8):487-497.

6. Falk MH, Issels RD: Hyperthermia in oncology. Int J Hyperthermia 2001, 17(1):1-18.

7. Jones EL, Oleson JR, Prosnitz LR, Samulski TV, Vujaskovic Z, Yu D, Sanders LL, Dewhirst MW: Randomized trial of hyperthermia and radiation for superficial tumors. J Clin Oncol 2005, 23(13):3079-3085.

8. Moroz P, Jones SK, Gray BN: Magnetically mediated hyperthermia: current status and future directions. Int J Hyperthermia 2002, 18(4):267-284.

9. Hand JW, Vernon CC, Prior MV: Early experience of a commercial scanned focused ultrasound hyperthermia system. Int J Hyperthermia 1992, 8(5):587-607.

10. Gardner RA, Vargas HI, Block JB, Vogel CL, Fenn AJ, Kuehl GV, Doval M: Focused microwave phased array thermotherapy for primary breast cancer. Ann Surg Oncol 2002, 9(4):326-332.

11. Abe M, Hiraoka M, Takahashi M, Egawa S, Matsuda C, Onoyama Y, Morita K, Kakehi M, Sugahara T: Multi-institutional studies on hyperthermia using an 8-MHz radiofrequency capacitive heating device (Thermotron RF-8) in combination with radiation for cancer therapy. Cancer 1986, 58(8):1589-1595.

12. Ito A, Tanaka K, Honda H, Abe S, Yamaguchi H, Kobayashi T: Complete regression of mouse mammary carcinoma with a size greater than $15 \mathrm{~mm}$ by frequent repeated hyperthermia using magnetite nanoparticles. J Biosci Bioeng 2003, 96(4):364-369.

13. Moroi J, Kashiwagi S, Kim S, Urakawa M, Ito H, Yamaguchi K: Regional differences in apoptosis in murine gliosarcoma (T9) induced by mild hyperthermia. Int J Hyperthermia 1996, 12(3):345-354.

14. Roti Roti JL: Cellular responses to hyperthermia (40-46 degrees C): cell killing and molecular events. Int J Hyperthermia 2008, 24(1):3-15.

15. Kampinga HH, Dynlacht JR, Dikomey E: Mechanism of radiosensitization by hyperthermia ( $>$ or $=43$ degrees $C$ ) as derived from studies with DNA repair defective mutant cell lines. Int J Hyperthermia 2004, 20(2):131-139.

16. Koutcher JA, Barnett D, Kornblith AB, Cowburn D, Brady TJ, Gerweck LE: Relationship of changes in $\mathrm{pH}$ and energy status to hypoxic cell fraction and hyperthermia sensitivity. Int J Radiat Oncol Biol Phys 1990, 18(6):1429-1435.

17. Atanackovic D, Nierhaus A, Neumeier M, Hossfeld DK, Hegewisch-Becker S: 41.8 degrees $C$ whole body hyperthermia as an adjunct to chemotherapy induces prolonged T cell activation in patients with various malignant diseases. Cancer Immunol Immunother 2002, 51(11-12):603-613.

18. Multhoff G: Heat shock protein 72 (HSP72), a hyperthermia-inducible immunogenic determinant on leukemic K562 and Ewing's sarcoma cells. Int J Hyperthermia 1997, 13(1):39-48.

19. Milani V, Frankenberger B, Heinz O, Brandl A, Ruhland S, Issels RD, Noessner E: Melanoma-associated antigen tyrosinase but not Melan-A/MART-1 expression and presentation dissociate during the heat shock response. Int Immunol 2005, 17(3):257-268.

20. Tabuchi Y, Wada S, Furusawa Y, Ohtsuka K, Kondo T: Gene networks related to the cell death elicited by hyperthermia in human oral squamous cell carcinoma HSC-3 cells. Int J Mol Med 2012, 29(3):380-386.

21. Furusawa Y, Tabuchi Y, Wada S, Takasaki I, Ohtsuka K, Kondo T: Identification of biological functions and gene networks regulated by heat stress in U937 human lymphoma cells. Int J Mol Med 2011, 28(2):143-151.

22. Tabuchi Y, Takasaki I, Wada S, Zhao QL, Hori T, Nomura T, Ohtsuka K, Kondo $\mathrm{T}$ : Genes and genetic networks responsive to mild hyperthermia in human lymphoma U937 cells. Int J Hyperthermia 2008, 24(8):613-622.

23. Boopalan T, Arumugam A, Damodaran C, Rajkumar L: The anticancer effect of 2'-3'-dehydrosalannol on triple-negative breast cancer cells. Anticancer Res 2012, 32(7):2801-2806.

24. Mitchell DC, Abdelrahim M, Weng J, Stafford LJ, Safe S, Bar-Eli M, Liu M: Regulation of KiSS-1 metastasis suppressor gene expression in breast cancer cells by direct interaction of transcription factors activator protein-2alpha and specificity protein-1. J Biol Chem 2006, 281(1):51-58.

25. Meng L, Hunt C, Yaglom JA, Gabai VL, Sherman MY: Heat shock protein Hsp72 plays an essential role in Her2-induced mammary tumorigenesis. Oncogene 2011, 30(25):2836-2845

26. Stiles JM, Amaya C, Rains S, Diaz D, Pham R, Battiste J, Modiano JF, Kokta V Boucheron LE, Mitchell DC, et al: Targeting of beta adrenergic receptors results in therapeutic efficacy against models of hemangioendothelioma and angiosarcoma. PLoS One 2013, 8(3):e60021. 
27. Ito $\mathrm{A}$, Honda $\mathrm{H}$, Kobayashi $\mathrm{T}$ : Cancer immunotherapy based on intracellular hyperthermia using magnetite nanoparticles: a novel concept of "heat-controlled necrosis" with heat shock protein expression. Cancer Immunol Immunother 2006, 55(3):320-328.

28. Samali A, Cotter TG: Heat shock proteins increase resistance to apoptosis. Exp Cell Res 1996, 223(1):163-170.

29. Beere HM: "The stress of dying": the role of heat shock proteins in the regulation of apoptosis. J Cell Sci 2004, 117(Pt 13):2641-2651.

30. Ciocca DR, Calderwood SK: Heat shock proteins in cancer: diagnostic, prognostic, predictive, and treatment implications. Cell Stress Chaperones 2005, 10(2):86-103

31. Gyrd-Hansen M, Nylandsted J, Jaattela M: Heat shock protein 70 promotes cancer cell viability by safeguarding lysosomal integrity. Cell Cycle 2004, 3(12):1484-1485.

32. Vargas-Roig LM, Gago FE, Tello O, Aznar JC, Ciocca DR: Heat shock protein expression and drug resistance in breast cancer patients treated with induction chemotherapy. Int J Cancer 1998, 79(5):468-475.

33. Mackey MA, Morgan WF, Dewey WC: Nuclear fragmentation and premature chromosome condensation induced by heat shock in S-phase Chinese hamster ovary cells. Cancer Res 1988, 48(22):6478-6483.

34. Genet SC, Fujii Y, Maeda J, Kaneko M, Genet MD, Miyagawa K, Kato TA Hyperthermia inhibits homologous recombination repair and sensitizes cells to ionizing radiation in a time and temperature dependent manner. J Cell Physio 2012, 228(7):1473-1481.

35. Krawczyk PM, Eppink B, Essers J, Stap J, Rodermond H, Odijk H, Zelensky A, van Bree C, Stalpers $L$, Buist MR, et al: Mild hyperthermia inhibits homologous recombination, induces BRCA2 degradation, and sensitizes cancer cells to poly (ADP-ribose) polymerase-1 inhibition. Proc Natl Acad Sci U S A 2011, 108(24):9851-9856.

36. Eppink B, Krawczyk PM, Stap J, Kanaar R: Hyperthermia-induced DNA repair deficiency suggests novel therapeutic anti-cancer strategies. Int J Hyperthermia 2012, 28(6):509-517.

37. Hunt CR, Pandita RK, Laszlo A, Higashikubo R, Agarwal M, Kitamura T, Gupta A, Rief N, Horikoshi N, Baskaran R, et al: Hyperthermia activates a subset of ataxia-telangiectasia mutated effectors independent of DNA strand breaks and heat shock protein 70 status. Cancer Res 2007, 67(7):3010-3017

38. Shin H, Lee H, Fejes AP, Baillie DL, Koo HS, Jones SJ: Gene expression profiling of oxidative stress response of $C$. elegans aging defective AMPK mutants using massively parallel transcriptome sequencing. BMC Res Notes 2011, 4:34

39. Gupta A, Cooper ZA, Tulapurkar ME, Potla R, Maity T, Hasday JD, Singh IS: Toll-like receptor agonists and febrile range hyperthermia synergize to induce heat shock protein 70 expression and extracellular release. J Biol Chem 2013, 288(4):2756-2766

40. Kim H, Heo K, Choi J, Kim K, An W: Histone variant H3.3 stimulates HSP70 transcription through cooperation with HP1gamma. Nucleic Acids Res 2011, 39(19):8329-8341.

41. Michel Cl, Holley CL, Scruggs BS, Sidhu R, Brookheart RT, Listenberger LL, Behlke MA, Ory DS, Schaffer JE: Small nucleolar RNAs U32a, U33, and U35a are critical mediators of metabolic stress. Cell Metab 2011, 14(1):33-44

42. Cohen E, Avrahami D, Frid K, Canello T, Levy Lahad E, Zeligson S, Perlberg S, Chapman J, Cohen OS, Kahana E, et al: Snord 3A: a molecular marker and modulator of prion disease progression. PLOS One 2013, 8(1):e54433.

43. Stepanov GA, Semenov DV, Kuligina EV, Koval OA, Rabinov IV, Kit YY, Richter VA: Analogues of Artificial Human Box C/D Small Nucleolar RNA As Regulators of Alternative Splicing of a pre-mRNA Target. Acta Nat 2012, 4(1):32-41.

44. Zhao R, Kakihara Y, Gribun A, Huen J, Yang G, Khanna M, Costanzo M, Brost RL, Boone C, Hughes TR, et al: Molecular chaperone Hsp90 stabilizes Pih1/ Nop17 to maintain R2TP complex activity that regulates snoRNA accumulation. J Cell Biol 2008, 180(3):563-578.

45. Boulon S, Marmier-Gourrier N, Pradet-Balade B, Wurth L, Verheggen C, Jady BE, Rothe B, Pescia C, Robert MC, Kiss T, et al: The Hsp90 chaperone controls the biogenesis of L7Ae RNPs through conserved machinery. J Cell Biol 2008, 180(3):579-595.

46. Eckert K, Saliou JM, Monlezun L, Vigouroux A, Atmane N, Caillat C, Quevillon-Cheruel S, Madiona K, Nicaise M, Lazereg S, et al: The Pih1-Tah1 cochaperone complex inhibits Hsp90 molecular chaperone ATPase activity. J Biol Chem 2010, 285(41):31304-31312.
47. Roti Roti JL: Heat-induced alterations of nuclear protein associations and their effects on DNA repair and replication. Int J Hyperthermia 2007, 23(1):3-15.

48. Mackey MA, lanzini F: Enhancement of radiation-induced mitotic catastrophe by moderate hyperthermia. Int J Radiat Biol 2000, 76(2):273-280.

49. Debec A, Marcaillou C: Structural alterations of the mitotic apparatus induced by the heat shock response in Drosophila cells. Biol Cell 1997, 89(1):67-78

50. Westra A, Dewey WC: Variation in sensitivity to heat shock during the cell-cycle of Chinese hamster cells in vitro. Int J Radiat Biol Relat Stud Phys Chem Med 1971, 19(5):467-477.

51. Dewey WC: Failla memorial lecture. The search for critical cellular targets damaged by heat. Radiat Res 1989, 120(2):191-204.

52. Coss RA, Dewey WC, Bamburg JR: Effects of hyperthermia on dividing Chinese hamster ovary cells and on microtubules in vitro. Cancer Res 1982, 42(3):1059-1071.

53. Vidair CA, Dewey WC: Two distinct modes of hyperthermic cell death. Radiat Res 1988, 116(1):157-171.

doi:10.1186/1471-2407-14-81

Cite this article as: Amaya et al:: A genomics approach to identify susceptibilities of breast cancer cells to "fever-range" hyperthermia. BMC Cancer 2014 14:81.

\section{Submit your next manuscript to BioMed Central and take full advantage of:}

- Convenient online submission

- Thorough peer review

- No space constraints or color figure charges

- Immediate publication on acceptance

- Inclusion in PubMed, CAS, Scopus and Google Scholar

- Research which is freely available for redistribution 